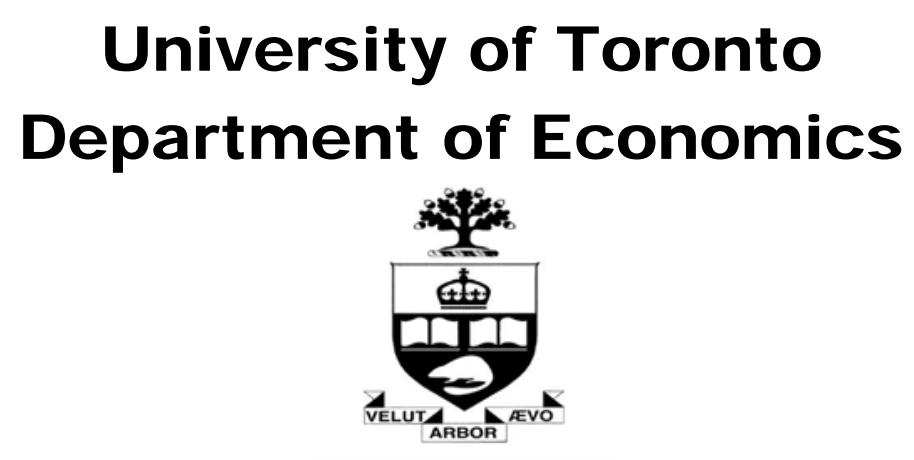

Working Paper 576

Complex-Task Biased Technological Change and the Labor Market

\author{
By Colin Caines, Florian Hoffmann and Gueorgui Kambourov
}

January 28,2017 


\title{
Complex-Task Biased Technological Change and the Labor Market*
}

\author{
Colin Caines ${ }^{\dagger} \ddagger$ \\ Federal Reserve Board
}

\author{
Florian Hoffmann ${ }^{\S}$ \\ University of British Columbia
}

\author{
Gueorgui Kambourov \\ University of Toronto
}

\begin{abstract}
In this paper we study the relationship between task complexity and the occupational wageand employment structure. Complex tasks are defined as those requiring higher-order skills, such as the ability to abstract, solve problems, make decisions, or communicate effectively. We measure the task complexity of an occupation by performing Principal Component Analysis on a broad set of occupational descriptors in the Occupational Information Network $\left(\mathrm{O}^{*} \mathrm{NET}\right)$ data. We establish four main empirical facts for the U.S. over the 1980-2005 time period that are robust to the inclusion of a detailed set of controls, subsamples, and levels of aggregation: (1) There is a positive relationship across occupations between task complexity and wages and wage growth; (2) Conditional on task complexity, routine-intensity of an occupation is not a significant predictor of wage growth and wage levels; (3) Labor has reallocated from less complex to more complex occupations over time; (4) Within groups of occupations with similar task complexity labor has reallocated to non-routine occupations over time. We then formulate a model of Complex-Task Biased Technological Change with heterogeneous skills and show analytically that it can rationalize these facts. We conclude that workers in non-routine occupations with low ability of solving complex tasks are not shielded from the labor market effects of automatization.
\end{abstract}

Keywords: Occupational Task Content; Complex Tasks; Wage Polarization; Skills

JEL Classification: E24, J21, J23, J24, J31

${ }^{*}$ This version: January 27, 2017. We thank Lance Lochner, Jaromir Nosal, an anonymous referee, and participants at the "Human Capital and Inequality Conference" at the University of Chicago for their comments and suggestions. Kambourov has received funding from the Social Sciences and Humanities Research Council of Canada grant \#4352014-0815 and from the European Research Council under the European Union's Seventh Framework Programme (FP7/2007-2013)/ERC grant agreement n. 324085.

${ }^{\dagger}$ The views in this paper are solely the responsibility of the authors and should not be interpreted as reflecting the views of the Board of Governors of the Federal Reserve System or of any other person associated with the Federal Reserve Board.

${ }^{\ddagger}$ Division of International Finance, Board of Governors of the Federal Reserve System, Washington, D.C., 20551, U.S.A. E-mail: colin.c.caines@frb.gov.

${ }^{\S}$ Department of Economics, University of British Columbia, 6000 Iona Drive, Vancouver, BC, V6T 1Z4, Canada. E-mail: Florian.Hoffmann@ubc.ca.

`University of Toronto, Department of Economics, 150 St. George St., Toronto, Ontario M5S 3G7, Canada. E-mail: g.kambourov@utoronto.ca. 


\section{Introduction}

A recent literature on wage and earnings inequality emphasizes the role of occupations for understanding trends in the aggregate wage- and employment structure. A common motivation for this emphasis is the well-established finding that skill-biased technological change (SBTC) cannot account for important changes in the relationship between skills and labor market outcomes. Particularly noteworthy is recent evidence that occupations which formerly offered middle-class and middle-skill jobs have lost ground in terms of wage and employment relative to both low- and high wage jobs. A popular explanation for this finding, quickly replacing the SBTC hypothesis as the primary theoretical economic framework for studying trends in wage inequality, is routine-biased technological change (RBTC). According to this view occupations are defined by bundles of tasks, and middle-skill occupations have been under pressure of automatization over the last few decades because they are intensive in routine tasks. This view can be justified theoretically from what Autor and Acemoglu (2011) call Ricardian models of the labor market in which it is the comparative advantage of workers in non-routine jobs that determines their labor market outcomes rather than a unidimensional measure of skills, such as education. For routine jobs to lose relative to former low-wage jobs one needs to assume a skill structure that segments labor markets according to whether workers can be replaced by machines or not.

Figure 1: Distribution of Hourly Wage Growth for Routine and Non-Routine Occupations
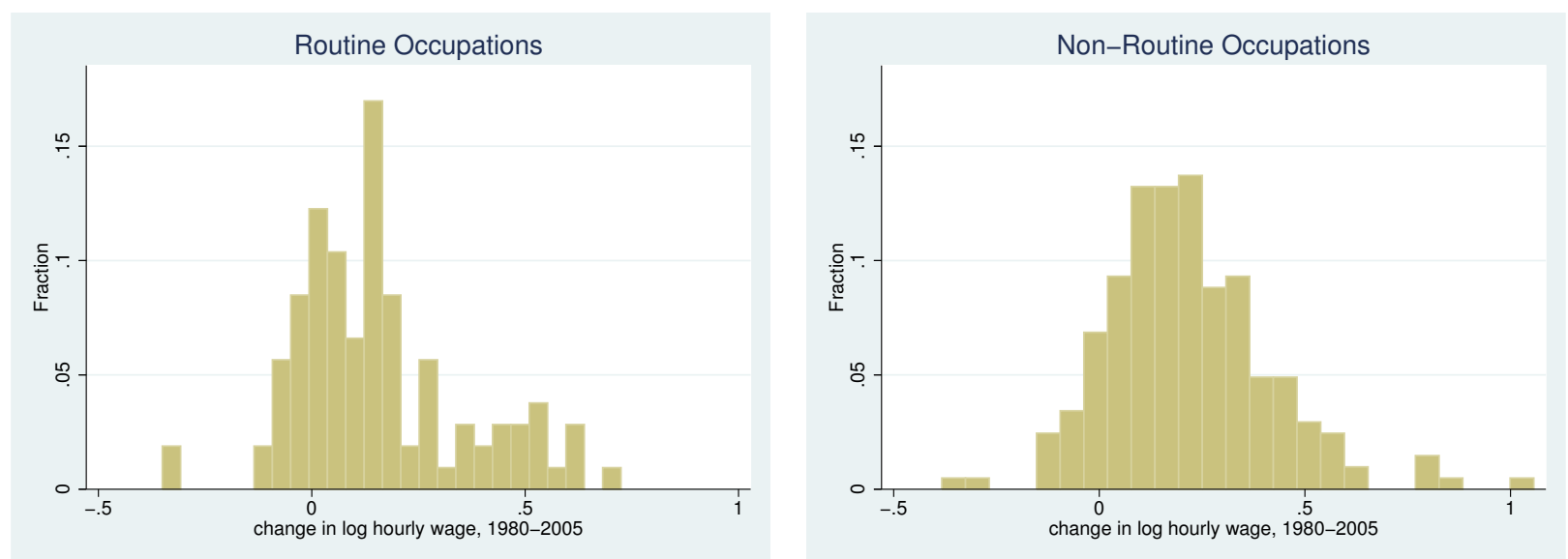

Notes: Data taken from the 1980 5\% Sample of the US Census and the 2005 American Community Survey (ACS). Hourly wages constructed from total wage and salary data (adjusted using PCE deflator), number of weeks worked per year, and usual number of hours worked per year. Data is defined on the 3-digit occupation level. Routine occupations defined as in Autor and Dorn (2013), all other occupations defined as non-routine.

The view that routine task intensity of occupations is the central predictor of wage and employment growth is not uncontroversial however. For example, Katz (2014) highlights the growing importance of artisanal work that combines creativity with crafting skills to customize and refine consumption goods. Indeed, many crafts occupations that are commonly classified as manual 
routine have fared quite well in terms of labor market performance over the last three decades. More generally, the relationship between routine task-intensity and wage growth is far from perfect. Inspecting the distribution of real wage growth between 1980 and 2005 split by routine and non-routine occupations, computed from US Census data and the American Community Survey (ACS) and shown in Figure 1, reveals that both routine and non-routine occupations feature a significant share of low- and high wage growth occupations. ${ }^{1}$ It is therefore natural to ask whether labor markets for routine task intense occupations can be viewed as segmented from the rest of the economy, or whether some routine and non-routine occupations are subject to the same aggregate forces determining wages and employment. For example, machine operators, the quintessential example of routine occupations, may compete in the same labor markets as the non-routine occupation truck drivers, so that their labor market performance may be more tightly related than predicted by common formulations of RBTC. In fact, wage growth in these two occupations line up quite closely.

In this paper we thus offer an alternative view of the mechanism behind recent changes in the occupational wage- and employment structure. We hypothesize that it is task complexity - that is whether a task involves higher-order skills such as the ability to abstract, solve problems, making decisions, or communicate effectively - rather than routine-intensity that is a prime determinant of wages as well as both wage- and employment growth on the occupational level. According to this view, non-routine and routine occupations that are similar with respect to task complexity will compete in the same labor market, and they are predicted to perform similarly in terms of wages and wage growth. This view is motivated as follows. Occupations with the lowest level of task complexity, which we refer to as simple occupations, involve tasks that involve raw physical, cognitive and interactive skills and abilities only, that is those that carry us through every-day life. Prominent examples are carrying, driving, archiving, cleaning or over-the-counter interaction. Labor supply that can solve such tasks, whether they are in competition with machines or not, can therefore be viewed as abundant. In contrast, complex tasks involve higher-order skills, either innate or acquired via post-secondary education or other forms of human capital investments, and are therefore relatively scarce. If technological progress is complementary with task complexity, then we should observe a strong relationship between complex-task intensity and wage- and employment growth at the occupational level. Hence, an important distinction to existing theories of the occupational wage- and employment structure is that once one conditions on task complexity, then wages, as well as wage growth, are unrelated with routine task intensity or whether an occupation involves the production of goods or services. Consistent with this hypothesis, or with the discussion in Katz (2014) about the growing importance of artisanal work, we find that many crafts occupations are complex and have performed quite well over the last few decades.

\footnotetext{
${ }^{1}$ Similarly, Dustmann et al. (2009), Green and Sand (2014), and Goos et al. (2014) find that the changes in the occupational employment structure is at best weakly reflected in the changes of the occupational wage structure.
} 
To measure task complexity at the occupational level we closely follow the methodology of Yamaguchi (2012), however we apply this to data from the Occupational Information Network $\left(\mathrm{O}^{*} \mathrm{NET}\right)$ instead of the Dictionary of Occupational Titles (DOT). In a first step we select a large list of occupational descriptors that very clearly relate to our notion of task complexity, such as fluency of ideas, complex problem solving, or analyzing data and information. In a second step we aggregate this list of descriptors together with their documented intensity to a single measure using Principal Component Analysis (PCA) and merge it with occupation-level data on wage- and employment growth between 1980 and 2005 from the US Census and ACS. ${ }^{2}$

We then document four stylized facts. First, conditional on our measure of task complexity there were no significant wage differences between routine and non-routine jobs at either the beginning or the end of our sample period. Second, occupations with a high measure of task complexity had substantially higher wages and larger wage- and employment growth than simple occupations. Third, wages and wage growth in simple routine- and non-routine occupations were not statistically different, and their employment growth was negative. At the same time, the percent decline in employment in simple non-routine occupations was smaller than in the simple routine occupations. Finally, the wage growth differences are substantially larger than employment growth differences.

The main part of our empirical analysis tests whether the stylized facts about complex-task biased technological change continue to hold when controlling more flexibly for various occupational characteristics. To this end we estimate various regression models of wage levels in 1980 and 2005 and of 1980-2005 wage- and employment growth at the occupational level as a function of taskcomplexity and routine-task intensity. We find that wages and wage growth are indeed strongly positively related with task complexity, no matter if we use a continuous or a discrete measure, but unrelated to routine task intensity once one conditions on this measure. The relationship between employment growth and task complexity is also positive, but weaker. At the same time there is a weak, though robust, negative relationship between routine task intensity and employment growth. These results are robust to inclusion of various other occupational characteristics, such as average wages in 1980 and controls for education, age, race, gender, and social-skill intensity. Furthermore, they hold throughout the occupational wage distribution in 1980 and persist if we use data disaggregated further to groups defined by demographic characteristics.

To formalize our interpretation of these facts we formulate a simple stylized static general equilibrium model of Complex-Task Biased Technological Change. Loosely speaking, the model can be viewed as a hybrid of a Ricardian model with labor-replacing technological change in some occupations, as in Autor and Acemoglu (2011) and Autor and Dorn (2013), and the canonical model of SBTC, but with skill requirements measured by task complexity rather than education. More precisely, our model features three main components. First, we consider three production processes, called occupations, that differ with respect to their technologies and that aggregate into a single

\footnotetext{
${ }^{2}$ Caines et al. (2016) use an alternative procedure to identify complex occupations in German data.
} 
final output good. Simple routine and non-routine occupations draw from the same pool of labor supply, but the former is characterized by relative capital-skill substitutability while the latter, akin to low-skill services in Autor and Dorn (2013), only involve labor inputs. In contrast, labor in complex occupations is relatively complementary with capital. Second, workers are heterogeneous in terms of their ability to perform complex tasks and sort accordingly across simple and complex occupations. In equilibrium, worker behavior will be characterized by a threshold level of skills in solving complex tasks that allocates workers across simple and complex occupations. ${ }^{3}$ We show that under a simple and intuitive assumption on the complementarity of the three intermediate inputs in the production of the final good, the model can rationalize our empirical findings about the evolution of the occupational wage- and employment structure. A plausible exogenous force that can generate these changes is a relative increase in the factor productivity for the complex production process. We call this "Complex-Task Biased Technological Change." The economic mechanism underlying this result is similar also to the capital-skill complementarity channel emphasized in Krusell et al. (2000). They find that growth in the stock of equipment capital, such as computers and machines, combined with capital-skill complementarity is consistent with the increase in both the skill premium and the supply of highly skilled workers as observed in US data. Our framework is different along two important dimensions. First, we measure skill requirements by task complexity on the occupational level rather than educational attainment. Second, we introduce a distinction between routine and non-routine tasks and emphasize that they are not direct measures of inherent skills but rather different sets of tasks that may be performed by the same skill group.

It is insightful to briefly contrast our notion of technological change with alternative views put forward in the existing literature. First, compared with SBTC we take into account the possibility of labor-replacing technological progress whereby some workers are shifted from simple occupations in which labor is relatively substitutable with capital to simple occupations in which labor is the only input. At the same time, labor in complex occupations is subject to economic forces that are isomorphic to SBTC, but with skill requirements related to task complexity rather than the level of education. Second, in contrast to research that emphasizes the importance of routine task intensity, workers in non-routine occupations with a low level of complex-task intensity are not shielded from labor-replacing technological change. Rather, they compete in the same labor markets like workers in simple routine occupations and absorb any labor replaced by technological progress that does not have a sufficiently high level of skills for solving complex tasks. In practice, our approach identifies numerous occupations in the goods sector, especially those in the crafts, as complex occupations even though they are routine task intensive. Other examples are many middle-skill middle-rank occupations in finance and insurance. They are classified as routine since they are often embedded within a strict hierarchical firm structure and thus offer limited freedom

\footnotetext{
${ }^{3}$ More generally, one can think of our model as one with two-dimensional skills, one for performing simple tasks and one for performing complex tasks, but with the marginal distribution over simple skills assumed to be degenerate.
} 
to make independent decisions while our approach identifies them as complex. ${ }^{4}$ Third, recent work by Deming (2015) finds that the relevance of social skills in occupations is strongly related to occupation-level labor market outcomes. We view our approach as complementary with this work since most tasks involving social skills, such as managing or consulting, are also complex. However, they are not the same. Again, an important difference is that we predict that manualor cognitive task intensive occupations that do not involve a lot of social interaction can perform quite well, as long as they are complex. Examples are some craftsmen and mechanics on the one hand and mathematicians and statisticians on the other hand. Fourth, a number of studies, among them Beaudry et al. (2016), study the relationship between cognitive skill intensity and wage- and employment growth. Cognitive skill intensity is positively related to task complexity, but so are numerous manual tasks, distinguishing our approach from this line of research. Finally, this paper is related to the literature, e.g., Kambourov and Manovskii (2008, 2009a,b), that has emphasized the importance of occupation-specific human capital in understanding wages and wage growth from the late 1960s to the mid-1990s in the United States.

\section{Task Complexity of Occupations}

A central challenge of the task-based approach to occupations is measurement. In this section we discuss in detail how we construct our measure of task complexity at the 3-digit occupational level and document some aggregate trends motivating our definition of complex-task biased technological change. Since this involves matching our occupation-level task measures to labor market data we start with describing the sample we use to construct aggregate trends in wages and employment.

\subsection{Wage and Employment Data}

We compute data on the occupational wage and employment structure over time from the 1980 Census Integrated Public Use Microdata and the 2005 American Community Survey (ACS), imposing similar sample restrictions to Autor and Dorn (2013). Our working sample consists of non-farm workers in the mainland United States between the ages of 16 and 64 (inclusive). The main part of our empirical analysis focuses on males. ${ }^{5}$ We also omit from our sample individuals who are institutionalized. Wage data refers to hourly wages, constructed from the census data for total wage and salary income (adjusted using the PCE deflator), number of weeks worked per year, and usual number of hours worked per week. The employment share of an occupation is given by the total number of hours worked in an occupation in a year as a fraction of the total number of hours worked in the economy.

\footnotetext{
${ }^{4}$ This is characterized by a high intensity of the DOT-variable "adaptability to work requiring set limits, tolerances, or standards," used in Autor et al. (2003) for measuring the routineness of an occupation.

${ }^{5}$ Results for females are documented in Section 3.3.2
} 


\subsection{Classifying Occupations by Complexity}

Two sources of data are commonly used for quantifying the task content of occupations, the Dictionary of Occupational Titles (DOT) and its successor the Occupational Information Network $\left(\mathrm{O}^{*}\right.$ NET $)$ production database. ${ }^{6}$ The $\mathrm{O}^{*} \mathrm{NET}$ has the advantage of offering a much broader set of occupational descriptors, which allows for a more precise measurement of task complexity. Furthermore, task measures are derived from a survey of incumbent workers rather than occupational analysts, as is the case for the DOT. We therefore rely on O*NET data in this paper (O*NET 20.1, October 2015). ${ }^{7}$

The O*NET is a publicly available dataset sponsored by the US Department of Labor. It compiles information on standardized measurable characteristics of occupations, referred to as descriptors. In total it contains 277 occupational descriptors sorted into 6 broad categories. These include the activities/tasks involved in working in an occupation, the requirements and qualifications needed to work in an occupation, as well as the knowledge/interests of the typical worker in an occupation. ${ }^{8}$ In selecting the relevant descriptors and mapping them into a unidimensional measure of task complexity using a principal components analysis we closely follow Yamaguchi (2012), although our selection of descriptors is much broader. ${ }^{9}$ To be more precise we first identify $35 \mathrm{O}^{*}$ NET descriptors that relate to our definition of task complexity. These descriptors are drawn from three subsections of the O*NET: "Abilities" (contained in "Worker Characteristics"), "Skills" (contained in "Worker Requirements"), and "Generalized Work Activities" (contained in "Occupational Requirements"). Examples are "originality" and "inductive reasoning" from the abilities module, "complex problem solving" and "critical thinking" from the skills module, and "analyzing data or information" and "thinking creatively" from the activities module. The selected descriptors are evaluated with a consistent 0-7 scale that indicates the degree to which they are required to perform in a given occupation. In our view each of these is positively correlated with task complexity. As a second step we map the information contained in our selected occupational descriptors into a single dimension complexity score, converted to percentile rankings, via principal components analysis (PCA). ${ }^{10}$ A detailed description of this procedure is provided in Appendix A, and in appendix Table A.1 we also provide the full list of descriptors and their factor loadings. In Appendix $\mathrm{D}^{11}$, we list the complexity index for each of our 3 -digit occupations. ${ }^{12}$ The top 10 percent of occupations

\footnotetext{
${ }^{6}$ See Autor and Dorn (2013), Autor et al. (2003), Autor et al. (2008), Firpo et al. (2011), Goos et al. (2009), and Ross (2015).

${ }^{7}$ However, we have also carried out our analysis using the DOT, with similar results. They are available upon request.

${ }^{8}$ The categories are "Worker Characteristics," "Worker Requirements," "Experience Requirements," "Occupational Requirements," "Labor Market Characteristics," and "Occupation-Specific Information."

${ }^{9}$ See also Bacolod and Blum (2010).

${ }^{10}$ See Bacolod and Blum (2010) and Yamaguchi (2012).

${ }^{11}$ Appendices D-F are in the Online Appendix.

${ }^{12}$ The $\mathrm{O}^{*} \mathrm{NET}$ provides information for 997 different occupations coded using the O*NET-SOC taxonomy. In the empirical work that follows we use a time-consistent modification to the 1990 US Census occupational codes as the
} 
Table 1: Wages and Employment

\begin{tabular}{|c|c|c|c|c|c|c|}
\hline & \multirow[t]{2}{*}{$\log \left(\right.$ wage $\left._{1980}\right)$} & \multirow[t]{2}{*}{$\log \left(\right.$ wage $\left._{2005}\right)$} & \multirow[t]{2}{*}{$\Delta \log ($ wage $)$} & \multicolumn{2}{|c|}{$\begin{array}{l}\text { Employment } \\
\text { Share }\end{array}$} & \multirow[t]{2}{*}{$\begin{array}{c}\% \text { Employment } \\
\text { Change }\end{array}$} \\
\hline & & & & 1980 & 2005 & \\
\hline simple & 1.949 & 2.062 & 0.113 & 0.654 & 0.595 & -0.090 \\
\hline complex & 2.304 & 2.663 & 0.357 & 0.346 & 0.405 & 0.170 \\
\hline
\end{tabular}

Notes: Wage and employment data taken from 1980 5\% sample of the US Census and the 2005 ACS. Sample restricted to non-institutionalized males aged 16-64 in the mainland United States. Complex occupations defined as those whose complexity index is above the 66th percentile in the occupation-level complexity distribution. All other occupations are defined as simple. Also note that the table shows the percentage change in the employment shares of simple and complex occupations, not the change in the employment share. The latter sum to zero.

rated in the complexity ranking largely comprise professional, scientific/medical, and senior management occupations. Conversely, the 10 percent of occupations at the bottom of the complexity distribution predominantly consist of service occupations, such as various cleaning occupations, as well as some manual occupations, primarily those involving machine operation. In the middle of the complexity distribution we find a wide range of both service and goods-producing occupations. The latter tend to consist of mechanics, technicians, and craftsmen.

In Section 3 we use the continuous complexity index to provide a detailed analysis of the effect of an occupation's complexity on its wage level, as well as on its wage- and employment growth. As a preview of our main message, we classify all occupations into either simple or complex, ${ }^{13}$ and Table 1 provides a preliminary look at the main result in the paper: complex occupations have higher mean wages (in both 1980 and 2005) and have experienced higher wage and employment growth than simple occupations over the 1980-2005 time period. In particular, complex occupations experienced a wage growth of 36 percent over the period compared to a 11 percent wage growth in simple occupations. Furthermore, the employment share of complex occupations increased at the expense of simple occupations.

\subsection{Routine Intensity and its Relation to Task Complexity}

Our definition of complexity correlates with several aspects of occupational task content considered elsewhere in the literature. To make our definition of occupational complexity clear it is useful to discuss how it differs from these concepts. The "routineness" of occupations has been inten-

level of our analysis. O*NET-SOC codes are mapped into these occupation codes, and the descriptor values are imputed using Census employment shares to compute weighted averages where necessary.

${ }^{13}$ Occupations are classified as simple if they are below the 66 th percentile of our complexity index and as complex if they are above it. The facts are quantitatively robust to the choice of this cutoff. 
sively studied by the literature. This has typically denoted the extent to which an occupation is automatable or codifiable. The seminal study of the substitutability between processing technology and routine-intensive labor inputs is Autor et al. (2003) (ALM). Their approach of measuring routineness from the DOT has been widely replicated. More recent studies by Autor et al. (2006) (AKK) and Autor and Dorn (2013) (AD) have classified the routineness of occupations from three dimensions that they measured in the DOT: abstract task intensity, manual task intensity, and routine task intensity.

Table 2: Comparison of Complexity and Routinization

\begin{tabular}{ccc}
\hline \hline Routinizable Occupations with High Complex Content \\
Occupation & & \\
Title & Routine Index & Complexity Index \\
& Percentile & Percentile \\
Financial Managers & & \\
Real Estate Sales Occupations & 82.825 & 96.109 \\
Accountants and Auditors & 87.416 & 66.033 \\
Insurance Underwriters & 95.502 & 78.977 \\
Statistical Clerks & 95.976 & 65.348 \\
Clinical Laboratory Technologist and Technicians & 93.661 & 93.177 \\
Other Financial Specialists & 74.922 & 73.236 \\
& 77.201 & 75.251 \\
\hline
\end{tabular}

Non-Routinizable Occupations with Low Complex Content

\begin{tabular}{ccc}
\hline Occupation & & \\
Title & Routine Index \\
Percentile & $\begin{array}{c}\text { Complexity Index } \\
\text { Percentile }\end{array}$ & \\
Waiters and Waitresses & & 3.617 \\
Baggage Porters, Bellhops and Concierges & 12.038 & 26.968 \\
Recreation Facility Attendants & 9.357 & 11.736 \\
Taxi Cab Drivers and Chauffeurs & 27.036 & 28.085 \\
Personal Service Occupations & 5.054 & 30.395 \\
Bus Drivers & 26.624 & 6.419 \\
& 26.855 & 12.672 \\
\hline \hline
\end{tabular}

Notes: The table reports values of the routine and complexity indices for a selection of occupations. The index values are converted to percentiles of the occupaton-level distribution. See sections 2.2 and 2.3 for construction of the routine index and the complexity index. 
Table 3: Complexity, Routineness, Wages, and Employment

\begin{tabular}{|c|c|c|c|c|c|c|c|}
\hline & & \multirow[t]{2}{*}{$\log \left(\right.$ wage $\left._{1980}\right)$} & \multirow[t]{2}{*}{$\log \left(\right.$ wage $\left._{2005}\right)$} & \multirow[t]{2}{*}{$\Delta \log ($ wage $)$} & \multicolumn{2}{|c|}{$\begin{array}{l}\text { Employment } \\
\text { Share }\end{array}$} & \multirow[t]{2}{*}{$\begin{array}{c}\% \text { Employment } \\
\text { Change }\end{array}$} \\
\hline & & & & & 1980 & 2005 & \\
\hline \multirow[t]{2}{*}{ simple } & routine & 1.925 & 2.041 & 0.116 & 0.188 & 0.169 & -0.098 \\
\hline & nonroutine & 1.959 & 2.071 & 0.112 & 0.466 & 0.426 & -0.086 \\
\hline complex & & 2.304 & 2.663 & 0.357 & 0.346 & 0.405 & 0.170 \\
\hline
\end{tabular}

Notes: Wage and employment data taken from 1980 5\% sample of the US Census and the 2005 ACS. Sample restricted to non-institutionalized males aged 16-64 in the mainland United States. Complex occupations defined as those whose complexity index is above the 66th percentile in the occupation-level complexity distribution. All other occupations are defined as simple.

We compute the routine task intensity index developed in Autor and Dorn (2013) as follows

$$
\text { Routine Task Intensity }{ }_{o}=\ln \left(\text { Routine }_{o}\right)-\ln \left(\text { Manual }_{o}\right)-\ln \left(\text { Abstract }_{o}\right)
$$

As should be expected, the routine task intensity (RTI) is negatively correlated with our complexity index (the correlation coefficient between the complexity and RTI percentile is -0.3158). However, there are important differences. The first panel of Table 2 lists several examples of complex occupations that are routine-intensive - they contain a number of financial service occupations such as Accountants, Financial Managers, and Real Estate Sales occupations. One possible reason that they are designated as being quite routine is that these occupations are often embedded within a strict hierarchical firm structure. This may limit the latitude afforded to workers to make independent decisions and requires them to work to set standards. Nevertheless, we think of such occupations as requiring some specialized knowledge and requiring the ability to perform some abstract problem solving (such as mathematical calculations). In other words, they are likely to recruit from a different pool of workers than occupations that are in competition with computers (such as some clerical workers or machine operators). The second panel of Table 2 lists examples of non-routine occupations with low complexity ratings. These include several service occupations such as Waiters and Waitresses or Bus Drivers. While these occupations are difficult to replace with processing technology (and hence are relatively non-routine), we consider them to be simple as they do not require many higher-level skills nor do they involve much abstract problem solving. As a consequence, we think of them as entering a similar labor market to those who work in simple, routine occupations.

Table 3 builds on the results presented in Table 1 by separating all simple occupations into two groups: routine and non-routine. Following Autor and Dorn (2013) routine occupations are 
those for which the routine task intensity defined in (1) is ranked in the top third amongst all occupations. The distinction between simple routine and simple non-routine occupations will play an important role in our empirical analysis since it can be used to test the hypothesis of complextask biased technological change against the hypothesis of routine-biased technological change. The underlying theoretical framework will be developed in Section 4. The table shows mean wages as well as average wage and employment growth for the three occupational categories - simple routine, simple non-routine, and complex - and yields the following insights:

1. Wage levels and wage growth are higher in complex occupations than in simple occupations;

2. Within the simple occupations, wage levels as well as wage growth are the same for routine occupations and non-routine occupations;

3. There is reallocation from simple occupations to complex occupations over time;

4. Within the simple occupations, the routine occupations experienced a larger percent decline in employment over time than the non-routine occupations.

\section{Empirical Analysis}

This section presents the results from a detailed empirical analysis of the relationship between wages, wage- and employment growth, and task complexity at the occupational level in the 19802005 time period. Our empirical analysis consists of estimating separate regressions for our outcomes on measures of task complexity and routinization. We experiment with two ways of controlling for task complexity: (i) a continuous normalized measure of task complexity; specifically, a percentile in the distribution of our task complexity index computed via PCA, and (ii) a complexity dummy. Results from both of these approaches are presented in the tables below. We also offer a detailed analysis of robustness to adding more controls, splitting the sample in various ways, and disaggregating the data to a finer level. Importantly, for the wage growth and employment growth regressions we show results from specifications that include a flexible polynomial in the 1980 average occupational wage, a variable that is often used in the literature as a measure of the "absolute" skill content of an occupation. ${ }^{14}$

\subsection{Task Content of Occupations and Wage Levels}

We start by considering the relationship between the task complexity of an occupation and its place in the wage distribution. Table 4 reports results for individual-level regressions of log wages on the task complexity index and the routine task intensity index, together with fixed effects for age, education, and race. Both task indices are converted to percentiles and normalized to lie between

\footnotetext{
${ }^{14}$ We use a 3rd order polynomial. Adding higher orders does not change the results.
} 
zero and one. ${ }^{15}$ Results are reported for both the 1980 and 2005 cross-sections. There is a large and significant relationship between the task complexity of the occupation in which an individual works and their wage level. Since we use the percentile of the complexity index as the explanatory variable of interest, a coefficient value of 0.35 for the 1980 cross section has the interpretation that the mean wages of individuals in the most complex occupations are $35 \%$ higher than the mean wages of individuals in the least complex occupations. In the 2005 cross-section this gap increases to $71 \%$. For both years the routineness of an individual's occupation has no significant relationship with the mean wage after controlling for complexity.

In the analysis that follows we focus on the relationship between complexity and both wageand employment growth. Because we do not use panel data that follow individuals over time this requires aggregating to the occupation level. For comparability with the individual-level results for wage levels we first show an occupation-level analogue to Table 4 . Table 5 shows results for regressions of the log of mean occupational wages on task complexity and routine task intensity. The regressions include an array of demographic controls. These include the share of workers in an occupation with a college or high school degree, the share of workers in an occupation who are married or who are non-white, the occupational female employment share, as well as the average age and mean number of children for workers in the occupation.

Once again the task complexity index has a robust positive relationship with wage levels. The gap between the mean wage in the most and the least complex occupation is 10\% in 1980 and $40 \%$ in 2005. This is robust to controlling for the routineness of an occupation, which does not have a significant relationship with the occupation wage level. Table 5 also shows results for specifications where the complexity index is replaced by a complexity dummy. Here the results are stronger for the 2005 cross-section, with complex occupations having wages that are 8.6-11.5 percent higher than those in simple occupations, after controlling for demographic factors.

\footnotetext{
${ }^{15}$ Age consists of four categories (16-28, 29-40, 41-52, and 52-64), education consists of four categories (less than high school, high school, some college, and college), and race is consists of two categories (white and nonwhite).
} 
Table 4: Individual-Level Wage Regression, 1980 and 2005

\begin{tabular}{ccc}
\hline \hline Dependent Variable: Log Wages & \\
\hline Independent & & \\
Variable & 1980 & 2005 \\
\cline { 3 - 3 } Complexity Index & $0.347^{* * *}$ & $0.711^{* * *}$ \\
& $(7.25)$ & $(14.32)$ \\
Routine Index & & 0.0157 \\
& & $(0.31)$ \\
$N$ & & \\
& & \\
\hline \hline
\end{tabular}

Notes: The regressions include fixed effects for age (4 categories: 16-28, 29-40, 41-52, 53-64), education level (less than high school, high school, some college, college), and race (white, nonwhite). Standard errors clustered at occupation level. t-statistics are in parentheses. ${ }^{*} p<0.1 ;{ }^{* *} p<0.05 ;{ }^{* * *} p<0.01$.

\subsection{Task Content of Occupations, Wage Growth, and Employment Growth}

Table 6 shows results from baseline regressions of 1980-2005 wage growth on occupational task content. The independent variables in columns (i)-(iii) are the occupation task complexity index and the Autor and Dorn (2013) routine task intensity index (both converted to percentiles and normalized to lie between zero and one), a third-degree polynomial in the 1980 wage level, and the same set of occupation-level demographic means included in Table 5. Complexity has a positive and highly significant relationship with wage growth. This effect is robust to the inclusion of the 1980 wage level and the routineness index as control variables. Average wage growth between 1980 and 2005 in the most complex occupations is 30-35 percentage points higher than in the least complex occupations. It is notable that complexity has a significant relationship with wage growth even though the regressions include controls for the share of workers in an occupation with a college degree. In columns (iv) and (v) in Table 6 the complexity index is replaced with an indicator variable for complexity. Since the cutoff value of our complexity index that separates complex occupations from simple occupations is rather arbitrary, we show results from using the 50 th percentile in column (iv) and the 66th percentile in column (v). ${ }^{16}$ Wage growth in complex occupations is 7-14 percentage points higher than in simple occupations under the two cutoff levels,

\footnotetext{
${ }^{16}$ The findings are robust to the choice of the cutoff and additional results are available upon request.
} 
Table 5: Occupation-Level Wage Regression with Occupational Demographic Controls

\begin{tabular}{|c|c|c|c|c|c|c|c|c|}
\hline \multirow{3}{*}{$\begin{array}{c}\text { Indep. } \\
\text { Variable }\end{array}$} & \multicolumn{4}{|c|}{ (A) Dependent Variable: Log Wages in 1980} & \multicolumn{4}{|c|}{ (B) Dependent Variable: Log Wages in 2005} \\
\hline & \multicolumn{2}{|c|}{$\begin{array}{c}\text { Complex Variable: } \\
\text { Index }\end{array}$} & \multicolumn{2}{|c|}{$\begin{array}{l}\text { Complex Variable: } \\
\text { Indicator }^{\dagger}\end{array}$} & \multicolumn{2}{|c|}{$\begin{array}{c}\text { Complex Variable: } \\
\text { Index }\end{array}$} & \multicolumn{2}{|c|}{$\begin{array}{c}\text { Complex Variable: } \\
\text { Indicator }^{\dagger}\end{array}$} \\
\hline & (i) & (ii) & (iii) & (iv) & $(\mathrm{v})$ & (vi) & (vii) & (viii) \\
\hline Complexity & $0.102^{*}$ & $0.106^{*}$ & 0.00228 & 0.0235 & $0.401^{* * *}$ & $0.416^{* * *}$ & $0.115^{* * *}$ & $0.0862^{* *}$ \\
\hline Variable & $(1.71)$ & $(1.75)$ & $(0.08)$ & $(0.79)$ & $(5.31)$ & $(5.45)$ & $(3.29)$ & $(2.19)$ \\
\hline Routine & & 0.0131 & 0.00442 & 0.00846 & & 0.0512 & 0.0394 & 0.0317 \\
\hline Index & & $(0.41)$ & $(0.14)$ & $(0.26)$ & & $(1.28)$ & $(0.95)$ & $(0.76)$ \\
\hline Female & $-0.143^{* * *}$ & $-0.147 * * *$ & $-0.154^{* * *}$ & $-0.155^{* * *}$ & $-0.128^{* *}$ & $-0.143^{* * *}$ & $-0.159^{* * *}$ & $-0.174^{* * *}$ \\
\hline Share & $(-3.52)$ & $(-3.51)$ & $(-3.68)$ & $(-3.71)$ & $(-2.53)$ & $(-2.76)$ & $(-2.97)$ & $(-3.24)$ \\
\hline College & $0.260^{* * *}$ & $0.265^{* * *}$ & $0.325^{* * *}$ & $0.295^{* * *}$ & $0.530^{* * *}$ & $0.553^{* * *}$ & $0.715^{* * *}$ & $0.676^{* * *}$ \\
\hline Share & $(3.49)$ & $(3.50)$ & $(4.64)$ & $(3.74)$ & $(5.71)$ & $(5.85)$ & $(8.01)$ & $(6.61)$ \\
\hline High School & $0.427 * * *$ & $0.423^{* * *}$ & $0.468^{* * *}$ & $0.478^{* * *}$ & $0.361^{* *}$ & $0.345^{* *}$ & $0.441^{* * *}$ & $0.568^{* * *}$ \\
\hline Share & $(3.50)$ & $(3.45)$ & $(3.84)$ & $(3.97)$ & $(2.35)$ & $(2.24)$ & $(2.80)$ & $(3.64)$ \\
\hline Non-white & -0.284 & -0.282 & -0.269 & -0.279 & -0.172 & -0.164 & -0.0910 & -0.139 \\
\hline Share & $(-1.38)$ & $(-1.37)$ & $(-1.30)$ & $(-1.35)$ & $(-0.67)$ & $(-0.64)$ & $(-0.35)$ & $(-0.52)$ \\
\hline Married & $0.884^{* * *}$ & $0.868^{* * *}$ & $0.938^{* * *}$ & $0.922^{* * *}$ & $0.568^{*}$ & 0.509 & $0.701^{* *}$ & $0.717^{* *}$ \\
\hline Share & $(3.47)$ & $(3.37)$ & $(3.66)$ & $(3.60)$ & $(1.79)$ & $(1.59)$ & $(2.14)$ & $(2.17)$ \\
\hline Mean & $0.00845^{* *}$ & $0.00851^{* *}$ & $0.00835^{* *}$ & $0.00844^{* *}$ & $0.0104^{* *}$ & $0.0106^{* *}$ & 0.00822 & $0.00991^{*}$ \\
\hline Age & $(2.16)$ & $(2.17)$ & $(2.11)$ & $(2.14)$ & $(2.09)$ & $(2.13)$ & (1.61) & $(1.92)$ \\
\hline Mean \# & -0.0710 & -0.0644 & -0.0661 & -0.0699 & 0.0437 & 0.0692 & 0.0789 & 0.0583 \\
\hline Children & $(-0.64)$ & $(-0.57)$ & $(-0.59)$ & $(-0.62)$ & $(0.31)$ & $(0.49)$ & $(0.54)$ & $(0.39)$ \\
\hline$N$ & 315 & 315 & 315 & 315 & 310 & 310 & 310 & 310 \\
\hline
\end{tabular}

${ }^{\dagger}$ Complex occupations are defined as those above the 50th percentile (columns (iii) and (vii)) or above the 66th percentile (columns (iv) and (viii)) of the complexity index.

Notes: Demographic variables are occupation-level means of the share of workers in an occupation with a college/high-school degree, the share of workers in an occupation who are non-white, the share of workers in an occupation who are married, the share of female workers in an occupation, the mean age of workers in an occupation, and the mean number of children of workers in an occupation. t-statistics are in parentheses. Significance levels are: ${ }^{* * *} 1 \%,{ }^{* *} 5 \%,{ }^{*} 10 \%$. 
while routineness once again has no significant relationship with wage growth.

We repeat our baseline regressions using employment growth rather than wage growth as a dependent variable, and the results are reported in Table 7. The relationship between employment growth and complexity is weaker than the wage growth results shown in Table 6. The relationship between task complexity and employment growth is positive in all columns, however the coefficient is not significant. It is quite notable that after controlling for complexity there is no significant relationship between routineness and employment growth.

Group-Level Estimation. So far our empirical analysis has been performed on data aggregated to the occupation level. Another empirical approach would be to rely on panel data that includes individuals of different cohorts in 1980 and 2005. This would enable us to estimate occupationspecific age- and time effects from worker-level data. Unfortunately, such data do not exist, at least not with an appropriate sample size. We approximate this type of data by disaggregating our repeated cross-sections to a much finer level, defined by occupations and "groups." Groups are defined by gender, education, race, and age. We define four categories for education: (i) individuals with less than a high school diploma, (ii) individuals with a high school diploma only, (iii) individuals with some college education, but no degree; and (iv) individuals with a college degree. We also define four categories for age: (i) 16 to 28, (ii) 29 to 40, (iii) 41 to 52, and (iv) 52 to 64 . Finally, we use two categories for race: white and non-white. For each occupationdemographic cell we compute average wage and total employment changes from 1980 to 2005 using the $19805 \%$ Census and the 2005 ACS. ${ }^{17}$ This yields a total of 15142 cells. We estimate our baseline wage and employment growth regressions on the disaggregated data, but with fixed effects for the categories. ${ }^{18}$ The results are reported in Tables 8 and F.1 (in Appendix F), respectively. In all of these regressions the standard errors are clustered at the occupation level.

When we regress wage growth on our disaggregated data the relationship between complexity and wage growth identified thus far remains. The most complex occupations are predicted to have a wage growth that is $26-35$ percentage points higher than in the least complex occupations. This is consistent with the coefficient values estimated in the occupation level data (Table 6) and still significant at the $1 \%$ level. There is also a positive, though insignificant, relationship between routineness and wage growth.

Table F.1 shows the results from the group-level regressions for employment. Complexity has a positive and significant relationship with employment growth, while occupations with higher levels of routine intensity are now predicted to have significantly lower levels of employment growth. It should be noted that the relatively small magnitude of the coefficients in these regressions is a

\footnotetext{
${ }^{17}$ We use the same sample restrictions as before. However, in order to have enough number of observations in each cell we use both men and women in this analysis.

${ }^{18}$ To be clear, the regressions include gender $\times$ education $\times$ race $\times$ age fixed effects.
} 
Table 6: Occupation-Level Wage Growth Regression with Occupational Demographic Means

Dependent Variable: Change in Log Wages 1980-2005

\begin{tabular}{|c|c|c|c|c|c|}
\hline \multirow{2}{*}{$\begin{array}{c}\text { Independent } \\
\text { Variable }\end{array}$} & \multicolumn{3}{|c|}{$\begin{array}{l}\text { Complex Variable: } \\
\text { Index }\end{array}$} & \multicolumn{2}{|c|}{$\begin{array}{c}\text { Complex Variable: } \\
\text { Indicator }^{\dagger}\end{array}$} \\
\hline & (i) & (ii) & (iii) & (iv) & (v) \\
\hline Complexity Variable & $\begin{array}{c}0.304^{* * *} \\
(4.94)\end{array}$ & $\begin{array}{c}0.316^{* * *} \\
(5.07)\end{array}$ & $\begin{array}{c}0.347^{* * *} \\
(5.74)\end{array}$ & $\begin{array}{c}0.138^{* * *} \\
(5.02)\end{array}$ & $\begin{array}{c}0.0683^{* *} \\
(2.18)\end{array}$ \\
\hline Routine Index & & $\begin{array}{l}0.0398 \\
(1.21)\end{array}$ & $\begin{array}{l}0.0336 \\
(1.05)\end{array}$ & $\begin{array}{l}0.0262 \\
(0.81)\end{array}$ & $\begin{array}{l}0.0161 \\
(0.48)\end{array}$ \\
\hline Female Share & $\begin{array}{c}0.00599 \\
(0.15)\end{array}$ & $\begin{array}{c}-0.00561 \\
(-0.13)\end{array}$ & $\begin{array}{c}-0.0299 \\
(-0.71)\end{array}$ & $\begin{array}{l}-0.0267 \\
(-0.63)\end{array}$ & $\begin{array}{l}-0.0504 \\
(-1.15)\end{array}$ \\
\hline College Share & $\begin{array}{c}0.270^{* * *} \\
(3.56)\end{array}$ & $\begin{array}{c}0.288^{* * *} \\
(3.73)\end{array}$ & $\begin{array}{c}0.287^{* * * *} \\
(3.52)\end{array}$ & $\begin{array}{c}0.349 * * * \\
(4.37)\end{array}$ & $\begin{array}{c}0.381 * * * \\
(4.35)\end{array}$ \\
\hline High School Share & $\begin{array}{l}-0.102 \\
(-0.82)\end{array}$ & $\begin{array}{l}-0.115 \\
(-0.91)\end{array}$ & $\begin{array}{l}0.0629 \\
(0.50)\end{array}$ & $\begin{array}{l}0.119 \\
(0.94)\end{array}$ & $\begin{array}{l}0.235^{*} \\
(1.81)\end{array}$ \\
\hline Non-white Share & $\begin{array}{l}0.106 \\
(0.51)\end{array}$ & $\begin{array}{l}0.112 \\
(0.54)\end{array}$ & $\begin{array}{l}0.0181 \\
(0.09)\end{array}$ & $\begin{array}{l}0.100 \\
(0.49)\end{array}$ & $\begin{array}{l}0.0551 \\
(0.26)\end{array}$ \\
\hline Married Share & $\begin{array}{l}-0.244 \\
(-0.94)\end{array}$ & $\begin{array}{l}-0.290 \\
(-1.11)\end{array}$ & $\begin{array}{l}0.0537 \\
(0.20)\end{array}$ & $\begin{array}{l}0.232 \\
(0.87)\end{array}$ & $\begin{array}{l}0.209 \\
(0.76)\end{array}$ \\
\hline Mean Age & $\begin{array}{c}0.00207 \\
(0.51)\end{array}$ & $\begin{array}{c}0.00222 \\
(0.55)\end{array}$ & $\begin{array}{c}0.00364 \\
(0.90)\end{array}$ & $\begin{array}{c}0.000595 \\
(0.15)\end{array}$ & $\begin{array}{c}0.00271 \\
(0.64)\end{array}$ \\
\hline Mean \# Children & $\begin{array}{l}0.0549 \\
(0.48)\end{array}$ & $\begin{array}{r}0.0747 \\
(0.64)\end{array}$ & $\begin{array}{c}0.00478 \\
(0.04)\end{array}$ & $\begin{array}{l}-0.0198 \\
(-0.17)\end{array}$ & $\begin{array}{c}-0.00485 \\
(-0.04)\end{array}$ \\
\hline $\begin{array}{l}\text { Order of } 1980 \text { Wage Poly. } \\
\qquad N=310\end{array}$ & 0 & 0 & 3 & 3 & 3 \\
\hline
\end{tabular}

${ }^{\dagger}$ Complex occupations are defined as those above the 50th percentile (column (iv)) or above the 66th percentile (column (v)) of the complexity index.

Notes: Demographic variables are occupation-level means of the share of workers in an occupation with a college/high-school degree, the share of workers in an occupation who are non-white, the share of workers in an occupation who are married, the share of female workers in an occupation, the mean age of workers in an occupation, and the mean number of children of workers in an occupation. t-statistics are in parentheses. Significance levels are: ${ }^{* * *} 1 \%,{ }^{* *} 5 \%,{ }^{*} 10 \%$. 
Table 7: Occupation-Level Employment Growth Regression with Occupational Demographic Means

Dependent Variable: Change in Employment Share 1980-2005

\begin{tabular}{|c|c|c|c|c|c|}
\hline \multirow{2}{*}{$\begin{array}{c}\text { Independent } \\
\text { Variable }\end{array}$} & \multicolumn{3}{|c|}{ Complex Variable: } & \multicolumn{2}{|c|}{$\begin{array}{c}\text { Complex Variable: } \\
\text { Indicator }^{\dagger}\end{array}$} \\
\hline & (i) & (ii) & (iii) & (iv) & (v) \\
\hline Complexity Variable & $\begin{array}{c}0.00162 \\
(1.44)\end{array}$ & $\begin{array}{c}0.00135 \\
(1.19)\end{array}$ & $\begin{array}{c}0.00154 \\
(1.34)\end{array}$ & $\begin{array}{c}0.00000113 \\
(0.00)\end{array}$ & $\begin{array}{c}0.000876 \\
(1.56)\end{array}$ \\
\hline Routine Index & & $\begin{array}{c}-0.000871 \\
(-1.44)\end{array}$ & $\begin{array}{c}-0.000822 \\
(-1.34)\end{array}$ & $\begin{array}{c}-0.000961 \\
(-1.57)\end{array}$ & $\begin{array}{c}-0.000783 \\
(-1.27)\end{array}$ \\
\hline Female Share & $\begin{array}{c}0.000152 \\
(0.20)\end{array}$ & $\begin{array}{c}0.000407 \\
(0.52)\end{array}$ & $\begin{array}{c}0.000207 \\
(0.26)\end{array}$ & $\begin{array}{l}0.000131 \\
(0.16)\end{array}$ & $\begin{array}{l}0.0000781 \\
\quad(0.10)\end{array}$ \\
\hline College Share & $\begin{array}{c}0.000808 \\
(0.58)\end{array}$ & $\begin{array}{c}0.000419 \\
(0.29)\end{array}$ & $\begin{array}{c}0.000563 \\
(0.36)\end{array}$ & $\begin{array}{c}0.00136 \\
(0.89)\end{array}$ & $\begin{array}{c}0.000282 \\
(0.18)\end{array}$ \\
\hline High School Share & $\begin{array}{c}-0.00114 \\
(-0.50)\end{array}$ & $\begin{array}{c}-0.000878 \\
(-0.38)\end{array}$ & $\begin{array}{c}-0.000129 \\
(-0.05)\end{array}$ & $\begin{array}{l}0.000499 \\
(0.21)\end{array}$ & $\begin{array}{c}0.000791 \\
(0.33)\end{array}$ \\
\hline Non-white Share & $\begin{array}{c}-0.000418 \\
(-0.11)\end{array}$ & $\begin{array}{c}-0.000536 \\
(-0.14)\end{array}$ & $\begin{array}{c}-0.000877 \\
(-0.22)\end{array}$ & $\begin{array}{c}-0.000595 \\
(-0.15)\end{array}$ & $\begin{array}{c}-0.00102 \\
(-0.26)\end{array}$ \\
\hline Married Share & $\begin{array}{c}-0.00478 \\
(-1.00)\end{array}$ & $\begin{array}{c}-0.00375 \\
(-0.78)\end{array}$ & $\begin{array}{c}-0.00189 \\
(-0.37)\end{array}$ & $\begin{array}{c}-0.000950 \\
(-0.19)\end{array}$ & $\begin{array}{c}-0.00167 \\
(-0.33)\end{array}$ \\
\hline Mean Age & $\begin{array}{c}-0.00000104 \\
(-0.01)\end{array}$ & $\begin{array}{c}-0.00000499 \\
(-0.07)\end{array}$ & $\begin{array}{c}-0.00000580 \\
(-0.08)\end{array}$ & $\begin{array}{c}-0.0000103 \\
(-0.13)\end{array}$ & $\begin{array}{c}-0.00000498 \\
(-0.07)\end{array}$ \\
\hline Mean \# Children & $\begin{array}{c}0.000758 \\
(0.36)\end{array}$ & $\begin{array}{c}0.000317 \\
(0.15)\end{array}$ & $\begin{array}{c}0.0000537 \\
\quad(0.02)\end{array}$ & $\begin{array}{c}0.00000976 \\
(0.00)\end{array}$ & $\begin{array}{c}-0.0000621 \\
(-0.03)\end{array}$ \\
\hline $\begin{array}{l}\text { Order of } 1980 \text { Wage Poly. } \\
\qquad N=315\end{array}$ & 0 & 0 & 3 & 3 & 3 \\
\hline
\end{tabular}

${ }^{\dagger}$ Complex occupations are defined as those above the 50th percentile (column (iv)) or above the 66th percentile (column (v)) of the complexity index.

Notes: Demographic variables are occupation-level means of the share of workers in an occupation with a college/high-school degree, the share of workers in an occupation who are non-white, the share of workers in an occupation who are married, the share of female workers in an occupation, the mean age of workers in an occupation, and the mean number of children of workers in an occupation. t-statistics are in parentheses. Significance levels are: ${ }^{* * *} 1 \%,{ }^{* *} 5 \%,{ }^{*} 10 \%$. 
result of the disaggregation, as the dependent variable is the share of overall employment in each occupation-gender-education-age-race cell.

Overall, we conclude that the stylized facts motivating our definition of complex-task biased technological change presented in section 2.3 are robust to disaggregation to the occupational level and inclusion of the 1980 wage level. In particular, task complexity is strongly positively related with both wage growth and wage levels, while wages within occupations of similar complexity are equalized across routine and non-routine occupations. Furthermore, we find evidence that more complex occupations experienced higher employment growth, and labor in occupations of similar task complexity has reallocated slightly towards non-routine occupations. The relatively weak employment effects suggest that the skill structure in the economy makes labor movements relatively inelastic with respect to the complex task wage premium.

Table 8: Group-Level Wage Growth Regression

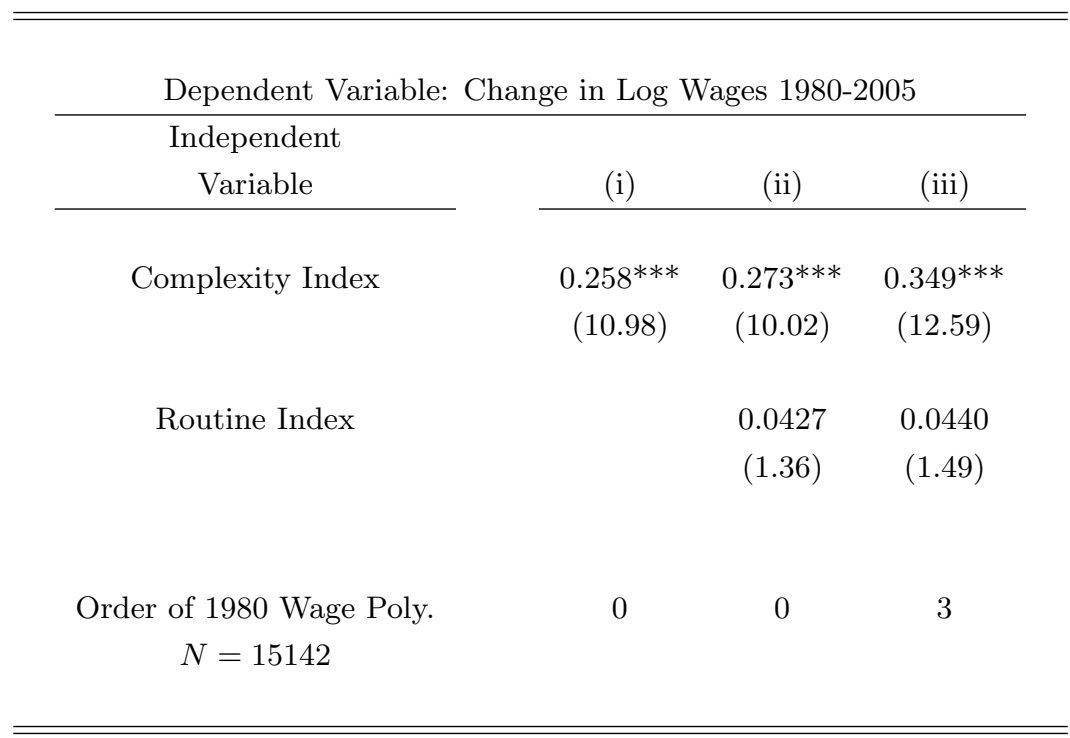

Notes: The table reports results when occupation-level data is disaggregated to occupation $\times$ gender $\times$ education $\times$ race $\times$ age cells $($ see section 3.2 ) for discussion. Regressions include gender $\times$ education $\times$ race $\times$ age fixed effects. Sandard errors clustered at the occupation level. t-statistics are in parentheses. Significance levels are: ${ }^{* * *} 1 \%,{ }^{* *} 5 \%,{ }^{*} 10 \%$.

\subsection{Robustness}

In this section we provide some sensitivity analysis on our wage and employment growth results.

\subsubsection{Complex-Task Biased Technological Change and the 1980 Wage Distribution}

A potential concern with our results is that they may be driven by a particular segment of the 1980 wage distribution. For example, Autor and Dorn (2013) argue that low-skill non-routine service 
sector jobs, which were at the bottom of the 1980 wage distribution, experienced substantial wage growth between 1980 and 2005. One may therefore wonder if our results do not hold for this part of the 1980 wage distribution and if they are mostly identified from formerly middle-wage and high-wage occupations. We thus split the sample by terciles of the 1980 wage distribution. The results for a specification with a third degree polynomial in the 1980 wage are shown in Table 9. The coefficient on task complexity is quite robust and estimated with high precision in all three subsamples. It is thus clear that our results hold no matter the wage level at the beginning of the sample period. Furthermore, the routine dummy is negative, though insignificant, in the first two subsamples. It is positive and significant among high-paying occupations, however. This is most likely driven by outliers since there are very few routine occupations among traditionally highpaying occupations. Corresponding results for employment growth are shown in Table F.2. Again, we find a robustly positive effect of task complexity and a robustly negative effect of routineness on employment growth for each tercile of the 1980 occupational wage distribution, though with insufficient statistical power to attain statistical significance. Interestingly, the employment effect of task complexity is strongest for the tercile with the highest estimated wage effect as well.

Table 9: Occupation-Level Wage Growth Regression by 1980 Wage Tercile

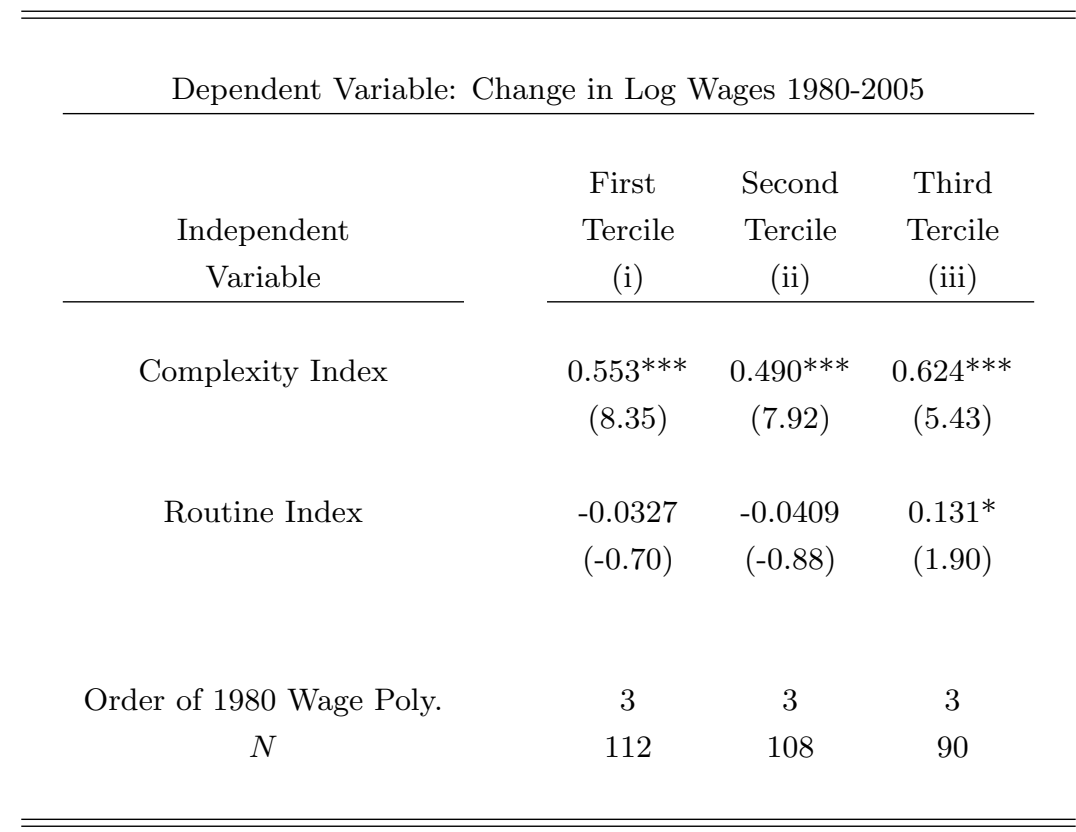

Notes: The table reports results for occupation-level regressions run for different terciles of the 1980 occupational wage distribution. t-statistics are in parentheses. Significance levels are: ${ }^{* * *} 1 \%,{ }^{* *} 5 \%,{ }^{*} 10 \%$. 


\subsubsection{Regressions on Female-Only Sample}

In our baseline analysis we excluded women from our wage and employment data, except in the group-level analysis in the previous section. This was done so as to abstract from the effects of increased female labor force participation and female wage growth during the sample. To examine the effect of this data restriction we now repeat our analysis using a female-only sample from the Census and the ACS, otherwise sample restrictions and variable construction remain unaltered.

Table F.3 reports results from the occupation-level wage growth regressions run on the femaleonly sample. The point estimates are similar to the corresponding results on the male sample reported in Table 6. Average wage growth in the most complex occupations is 36 to 38 percentage points higher than in the least complex occupations. When using the complexity dummies, instead of the index, the average wage growth for complex occupations is 9-12 percentage points higher than for simple occupations. Moreover, routine task intensity has no significant relationship with wage growth in the female-only sample.

As was the case with the baseline sample, task complexity has a weaker relationship with employment than with wages. Table F.4 reports the results for the occupation-level employment growth regressions carried out on the female-only sample. While the estimated coefficient on complexity is always positive, it is not significant. In contrast, routineness has a negative relationship with the 1980-2005 employment growth that is significant at the $5 \%$ level.

\section{Theoretical Framework}

\subsection{Overview}

We have documented four robust empirical facts about the evolution of the occupational wage and employment structure. These are: (i) wages, measured either in growth or in levels, are not significantly related to routine-task intensity once one conditions on task complexity; (ii) task complexity is strongly positively related to wage levels and wage growth; (iii) there has been a reallocation of labor from simple to complex occupations, and this employment growth effect is weaker than the growth in the complexity wage premium; (iv) within the simple occupations, the share of non-routine occupations has increased. In this section we formulate an equilibrium model of the occupational wage and employment structure that can jointly rationalize these facts.

To derive sharp theoretical results that clarify which modifications to the canonical model of SBTC are required we keep the model stylized. In particular, we consider a structure with three production processes only, called occupations, that differ with respect to their technologies and that aggregate into a single final output good. The three central features of the model are as follows. First, one of the occupation groups features capital-skill complementarity, where skill is measured by the ability to solve complex tasks. We call this group of occupations "complex". On the other hand, the ability to solve complex tasks is irrelevant in non-complex occupations. We refer to this 
group of occupations as "simple". Second, to highlight the distinction between task complexity and routineness, we divide simple occupations into two subgroups, namely simple-routine and simple non-routine occupations. Simple routine occupations are those that are gradually automated. Labor and capital are hence relatively substitutable. Simple non-routine occupations are akin to low-skill service jobs in Autor and Dorn (2013) and only require labor inputs. Third, workers are heterogeneous with respect to their skill endowment for performing complex tasks but are homogeneous in their ability to solve simple tasks. A direct consequence of this assumption is that simple occupations, whether routine or non-routine, draw from the same homogenous pool of labor supply. Wages are thus equalized among workers optimally choosing this group of occupations. This setup can be interpreted as a hybrid of the Ricardian model in Autor and Acemoglu (2011) and of a model of SBTC with capital-skill complementarity as in Krusell et al. (2000). Indeed, the technology in the complex and the simple routine occupations is a simplified version of the production function in Krusell et al. (2000), but with skills measured by the ability to solve complex tasks.

We derive comparative statics results for the case of an increase in the factor productivity of labor in the complex occupations. We call this case Complex-Task Biased Technological Change. Because of a shift in the demand for complex labor, the complexity wage premium increases. At the same time, more workers now find it optimal to move to the complex occupations, thereby worsening the skill composition and dampening the effect on the wage premium. How large this supply effect is depends on the characteristics of the complex-skill distribution. If this distribution is sufficiently skewed, with a large mass at the lower tail, then the labor supply to the complex occupations is relatively inelastic. In this case, the effect on the wage premium will be large while the employment effect will be relatively small. This widens the complexity wage premium because of the capital-complex-skill complementarity. The equilibrium adjustment of the employment structure in simple occupations is more complicated. Clearly, labor needs to flow from the simple to the complex occupations. Whether the decrease in simple routine- or non-routine labor inputs is larger in relative terms depends on the technologies. As it turns out, if capital and labor in simple routine occupations are sufficiently substitutable and intermediate outputs from routine and non-routine occupations are sufficiently complementary in the production of the final good, then the share of non-routine labor increases relative to the share of routine labor.

Taken together, our model features a production process in which workers with a certain type of skill gain from the introduction of new technologies, a production process in which new technologies substitute for workers, thereby integrating the concept of automatization, and a third production process that absorbs a (potentially substantial) share of "displaced" workers because it is nonroutine but simple. Interestingly, automatization in our comparative statics exercise does not arise from cheaper or more productive capital, but from the reallocation of labor towards an occupation in which computers and workers are complements. 
At this point it is worthwhile highlighting that we maintain the assumption that the distribution over simple tasks is degenerate, for two main reasons. First, it serves to highlight that we think of simple occupations as those involving tasks that most people need to perform at some point in their daily or weekly routine, such as driving, cleaning, preparing simple meals, archiving or transporting. As a consequence, simple non-routine occupations are a type of outside option available to anyone. Put differently, skills in performing simple tasks are in abundant supply relative to higher-order skills. Second, the model presented below remains tractable even though we solve for general equilibrium with heterogeneous workers.

An important consequence of this assumption is that our model only generates employment polarization, but not wage polarization. While this is consistent with the evidence for many nonUS countries, such as for Canada (Green and Sand (2014)) or for Germany (Dustmann et al. (2009)), there is a large literature documenting polarization of the occupational wage structure in US data. We do not attempt to modify the model to generate wage polarization as well and focus on the novel set of stylized facts we have established above. ${ }^{19}$

\subsection{The Model}

We consider a closed economy in which a final good $Y$ is produced using three intermediate production processes. Output from the three processes, defined by the tasks that need to be performed, is $\left(y_{c} ; y_{R} ; y_{N R}\right)$, where $s$ stands for "simple", $c$ stands for "complex", $R$ stands for "routine" and $N R$ stands for "non-routine". The mapping from intermediate to final output is given by the function

$$
Y=F_{Y}\left(y_{c} ; y_{R} ; y_{N R}\right)
$$

For reasons explained below, we impose the following functional form restrictions:

$$
\begin{aligned}
F_{Y} & =\left(y_{s}\right)^{\gamma} \cdot\left(y_{c}\right)^{1-\gamma}, \\
y_{s} & =\left[\left(y_{R}\right)^{\mu}+\left(y_{N R}\right)^{\mu}\right]^{\frac{1}{\mu}} .
\end{aligned}
$$

We will assume that $\gamma=0.5$ throughout the rest of the analysis. Output can be used either for producing capital, with technology

$$
K=\left(\frac{1}{\pi_{K}}\right) \cdot Y
$$

or for final consumption. Capital depreciates fully so that our economy can be viewed as a sequence of static economies. We therefore do not use a time-subscript.

\footnotetext{
${ }^{19}$ We conjecture that wage polarization can be delivered by our model as follows. Suppose that skills are twodimensional. In particular, skills in performing simple routine tasks are heterogeneous and positively correlated with skills in performing complex tasks. Then complex-task biased technological change will induce the highest earners in simple routine occupations to move to the complex occupations. As a consequence, the wage in simple routine occupations will decrease, while the wage in simple non-routine occupations, which do not depend on heterogeneous skills, will remain constant. While this extension is interesting for quantitative analysis, it will be analytically intractable.
} 
Let $C, S, K$ stand for aggregate inputs of labor performing complex or simple tasks and of capital, indexed appropriately in what follows. In specifying the production structure we assume that the elasticity of substitution between the capital input and the labor input is larger in the routine process than in the complex process. Hence, inputs of labor performing complex tasks are a relative complement with capital inputs. The non-routine process is modeled as in Autor and Dorn (2013), where it stands in for the manual non-routine labor intensive service sector. An example of such a production structure is a final output good that is produced using machines that need to be operated $\left(y_{R}\right)$ and that produce intermediates that need to be transported, stored and sold $\left(y_{N R}\right)$, thereby requiring organization, effective communication and management of the two processes $\left(y_{c}\right)$. For analytical convenience we impose the following production structure on these process:

$$
\begin{aligned}
y_{c} & =\left(\alpha_{c} \cdot C\right)^{\rho} \cdot\left(\alpha_{k, c} \cdot K_{c}\right)^{1-\rho}, \\
y_{R} & =\left[\alpha_{s, R} \cdot S_{R}^{\psi}+\alpha_{k, R} \cdot K_{R}^{\psi}\right]^{\frac{1}{\psi}}, \\
y_{N R} & =\alpha_{s, N R} \cdot S_{N R} .
\end{aligned}
$$

Relative capital-skill complementarity in the complex process implies that $\rho \in(0,1)$.

There is a unit mass of workers who are endowed with skills for performing simple or complex tasks, denoted by $(s, c)$. Each worker supplies one unit of labor inelastically. Skill endowments of $s$ are homogenous in the population, imposing the assumption that each worker has the same base level of skills at performing raw manual or simple communicative tasks, with implications discussed above in section 4.1. In contrast, skills at performing complex tasks are heterogeneous and distributed with CDF $G(c)$, which we assume to be of the Pareto-type with parameters $\left(\beta, c_{m}\right)$ :

$$
G(c)=1-\left(\frac{c_{m}}{c}\right)^{\beta}, \text { with } c \geq c_{m}
$$

The resource constraint that the mass of workers going to the complex process cannot be larger than one imposes the parameter restrictions $c_{m}<(\beta-1) / \beta$, with $\beta>1$. The parameters of the Pareto distribution turn out to be important for explaining why strong wage growth in non-routine simple occupations can come with weak employment growth in this occupation group.

Given these assumptions it is worth highlighting that the employment share of labor that goes to the simple occupations, $S$, is homogenous. In contrast, $C$ is an aggregator of heterogenous labor going to the complex sector:

$$
C=\int_{c^{T}}^{\infty} c \cdot d G(c)=\left(\frac{\beta}{\beta-1}\right) \cdot\left(c_{m}\right)^{\beta} \cdot\left(c^{T}\right)^{1-\beta} .
$$

The threshold level $c_{T}$ is endogenous and needs to be consistent with individual optimization (the threshold worker is indifferent between working in simple and complex tasks) and the labor market equilibrium condition $S=S_{R}+S_{N} R=G\left(c_{T}\right)$. 
The market structure is as follows. We treat this model economy as static so that we do not make any explicit assumptions about timing of events. Markets are perfectly competitive. One large representative firm owns the technology $F_{Y}$. It buys intermediate inputs at prices $p_{c}, p_{N R}$ and $p_{R}$ from three types of firms, each of which holds one of the intermediate technologies, and sells its final output to consumers at price $p_{Y}$. We treat the final good as the numeraire, with normalized price $p_{Y}=1$. Labor and capital is hired in competitive factor markets.

Since this economy is frictionless we characterize the equilibrium allocation by solving the social planner's problem. The planner's problem is outlined in Appendix B. Evidently, evaluated at the first-best allocation of labor and capital, all goods- and factor prices need to be equal to their marginal products. It is important to notice that in competitive equilibrium, $w_{N R}=p_{N R}$ and $w_{N R}=w_{R}$. Both of these equations are equilibrium conditions, the first of which states that profits in the non-routine process need to be zero and the second of which is a law-of-one-price for labor in the two simple production processes. Of course, these conditions also come out directly from the social planner's problem, as can be shown from its first-order conditions.

The equilibrium allocations do not admit closed-form solutions. Yet, the model can generate the empirical regularities documented above under a surprisingly clear restriction on the parameter space. Define $\mu^{*}=\beta /(\beta+\rho) \in(0,1)$. We then obtain the following result, proven in Appendix C.

Proposition. Consider two stationary state equilibrium allocations of labor together with their factor prices, $\left(C^{0}, S_{R}^{0}, S_{N R}^{0}, w_{c}^{0}, w_{R}^{0}, w_{N R}^{0}\right)$ and $\left(C^{1}, S_{R}^{1}, S_{N R}^{1}, w_{c}^{1}, w_{R}^{1}, w_{N R}^{1}\right)$. Assume that $\psi>$ $\mu>\mu^{*}$. Then an increase in the factor productivity of the labor input, $\alpha_{c}$ (or of the capital input, $\left.\alpha_{k, c}\right)$ in the complex technology, has the following effect on the equilibrium allocations and factor prices

$$
\begin{aligned}
C^{1} & >C^{0} \\
S_{R}^{1} & <S_{R}^{0} \\
S_{N R}^{1} & <S_{N R}^{0} \\
\frac{S_{N R}^{1}}{S_{R}^{1}} & >\frac{S_{N R}^{0}}{S_{R}^{0}} \\
w_{R}^{0} & =w_{N R}^{0} \\
w_{R}^{1} & =w_{N R}^{1} \\
\frac{w_{c}^{1}}{w_{N R}^{1}} & >\frac{w_{c}^{0}}{w_{N R}^{0}} .
\end{aligned}
$$




\subsection{Discussion}

Probably the deepest of the results in the proposition is the decline of the non-routine labor share when measured relative to the entire economy but an increase when measured relative to the total labor share of simple occupations. This result thus deserves some discussion. To understand the issue, suppose we set the parameter $\mu$ in equation (3) equal to zero so that the elasticity of substitution between all occupation-specific inputs in the production of the final good is equal to one. In this case the ratios of these intermediate inputs relative to total output produced, $y_{j} / Y$, are all kept constant. are kept constant. Since the only input in the non-routine occupation is labor it follows directly that $S_{N R}$ increases whenever $C$ increases. This is inconsistent with our stylized facts. We thus need to be able to control the complementarity between the two simple intermediate inputs in the production of the final good. This is achieved via the specification in equations (2) and (3). Notice that it will be optimal to keep the ratio of $y_{C}$ and $y_{S}$ constant. A rise in $y_{S}$ will thus have the effect of increasing the price of the simple intermediate inputs. With $p_{N R}=w_{N R}=w_{R}$, this will have the effect of increasing the relative cost of simple labor inputs. Since capital and labor are relatively substitutable in the routine occupation, there will be a strong

substitution towards capital inputs. For $\frac{S_{N R}}{S_{R}+S_{N R}}$ to increase while $S_{N R}$ decreases, $\mu$ can neither be too small nor too large. Indeed, if it was too small, $S_{N R}$ would increase rather than decrease. If it was too large, then $S_{N R}$ would decrease even faster than $S_{R}$. This explains the condition on the structural parameters in the proposition.

An interesting result not mentioned in the proposition is that the model is consistent with a situation in which the relative wage $\left(\frac{w_{C}}{w_{R}}\right)$ increases dramatically whereas the equilibrium employment share of the complex occupations $C^{*}$ rises only slightly. This can be seen from the following equation, derived in Appendix C:

$$
C^{*}=\left(\frac{\beta}{\beta-1}\right) \cdot c_{m}^{\beta} \cdot\left(\frac{w_{c}}{w_{R}}\right)^{\beta-1},
$$

where $c_{m}$ is the lower bound on labor in complex tasks, possibly zero, and $\beta>1$. Since equilibrium relative wages can be characterized without solving for $C^{*}$, as shown in Appendix $\mathrm{C}$, this equation should be interpreted as structural. It describes the equilibrium relationship between the complex wage premium and the labor share of the complex occupation. The strength of this relationship is governed by the parameters of the Pareto skill distribution, $\beta$ and $c_{m}$. It is then clear that one can find restrictions on the parameters of this distribution such that $d C^{*} \approx 0$ even though $d\left(w_{C} / w_{R}\right) \gg 0$. This will apply if $c_{m}$ is close to zero while $\beta$ is sufficiently large. With large $\beta$, the Pareto distribution is concentrated near $c_{m}$, and with small $c_{m}$ this point of concentration is quite far away from the threshold level $c_{T}$. Intuitively, if a large share of the population has very low skills at performing complex tasks, then the pool of labor optimally choosing the complex occupation is small and inelastic. As a consequence, demand shifts for complex labor have large 
effects on relative prices, but small effects on quantities.

Several additional points are worth noting. First, we refer to the situation in which the factor productivity in the complex technology rises as Complex-Task Biased Technological Change (CBTC). In principle the distinction between $\alpha_{c}$ and $\alpha_{k, c}$ is vacuous given the technology, but given our focus on the reallocation of labor rather than of capital we emphasize the case in which CBTC is kick-started by an increase of the factor productivity of complex labor inputs. Second, there are a number of other parameters that can generate the same qualitative predictions in comparative statics exercises. Examples include a decrease in price of capital, $\pi_{K}$, a case that may be particularly relevant given the evidence in Krusell et al. (2000), or an increase of the factor productivity of capital relative to labor in the simple routine technology, $\alpha_{k, R} / \alpha_{s, R}$. Which of these channels has the largest effect, and whether it can be identified, is an interesting question for future research. Third, any situation of complex-task biased technological change comes, by definition, with an increase of $C$. As this can only be the case if the skill threshold $c^{T}$ decreases, the average skill for performing complex tasks decreases in the process of labor reallocation. We provide empirical evidence suggestive of this effect in Appendix E.

\section{Complexity and Social Skills}

In a recent paper, Deming (2015) focuses on the role that social interaction skills play in explaining labor demand shifts over the past 30 years. He argues that such skills serve to reduce workerspecific coordination costs. Technological progress and automation have therefore implied that high-paying occupations increasingly require social skills. Consistent with this hypothesis, he finds that social skills have been increasingly rewarded over the last three decades, especially in jobs that combine social and cognitive skills. To compare our definition of complexity with social skills we compute a measure analogous to the social skill index in Deming (2015). Following Deming (2015) we select four occupational descriptors from the O*NET indicative of social skills: "Coordination", "Negotiation", "Persuasion", and "Social Perceptiveness". We carry out a PCA with one component on this data in order to compute social skill scores, which we in turn convert to percentiles between zero and one in order to yield a social skill index.

Social skills are correlated with complexity - the correlation coefficient between the two indices is 0.8951 . There are, however, important differences. The first panel in Table 10 lists several examples of complex occupations with relatively low social skill content. These are principally technical occupations such as Mathematicians and Statisticians, Computer Operators, and Programmers. These occupations clearly require abstract problem solving skills despite not involving a great deal of social interaction. Conversely, the second panel in Table 10 lists several examples of simple occupations with high social skill measures. These principally comprise service occupations such as Salespersons, Cleaning Supervisors, and Bill Collectors - occupations which are heavily 
Table 10: Comparison of Complexity and Social Skills

\begin{tabular}{ccc}
\hline \hline Occupations with High Complex Content and Low Social Skill Content \\
Occupation & & \\
Title & Social Skill & Complexity Index \\
& Percentile & Percentile \\
Computer and Peripheral Equipment Operators & 48.497 & \\
Aircraft Mechanics & 49.112 & 74.395 \\
Programmers of Numerically Controlled Machine Tools & 49.125 & 67.812 \\
Power Plant Operators & 49.648 & 71.556 \\
Mathematicians and Statisticians & 0.772 & 91.323 \\
Biological Technicians & 46.732 & 73.283 \\
& & \\
\hline
\end{tabular}

Occupations with Low Complex Content and High Social Skill Content

\begin{tabular}{ccc}
\hline Occupation & & \\
Title & $\begin{array}{c}\text { Social Skill } \\
\text { Percentile }\end{array}$ & $\begin{array}{c}\text { Complexity Index } \\
\text { Percentile }\end{array}$ \\
Retail Salespersons \& Sales Clerks & 62.228 & 49.662 \\
Bill and Account Collectors & 68.335 & 6.419 \\
Door-to-door Sales, Street Sales, and New Vendors & 70.040 & 44.817 \\
Supervisors of Clearning and Building Services & 62.962 & 32.372 \\
Eligibility Clerk for Government Programs & 56.290 & 44.825 \\
Sheriffs, Bailiffs, Correctional Institution Officers & 56.283 & 43.533 \\
& & \\
\hline \hline
\end{tabular}

Notes: The table reports values of the social skill and complexity indices for a selection of occupations. The index values are converted to percentiles of the occupation-level distribution. See sections 2.2 and 5 for the construction of the complexity and the social skill indices.

dependent on interacting with other people whilst not requiring a great deal of specific knowledge, management and organizational skills, or problem solving ability.

Table 11 presents preliminary evidence regarding the extent to which complexity and social skills have affected wage and employment growth in various occupations over the 1980-2005 time period. In particular, Table 11 shows average wage growth for 4 categories of occupations ${ }^{20}$ : simple nonsocial, simple social, complex nonsocial, and complex social. It is clear that it is the components of occupational complexity that principally explain wage patterns over the period. First, wage

\footnotetext{
${ }^{20}$ Social occupations are defined as those that have a social skill index in the top 66 th percent amongst all occupations.
} 
Table 11: Complexity, Social Skills, Wages, and Employment

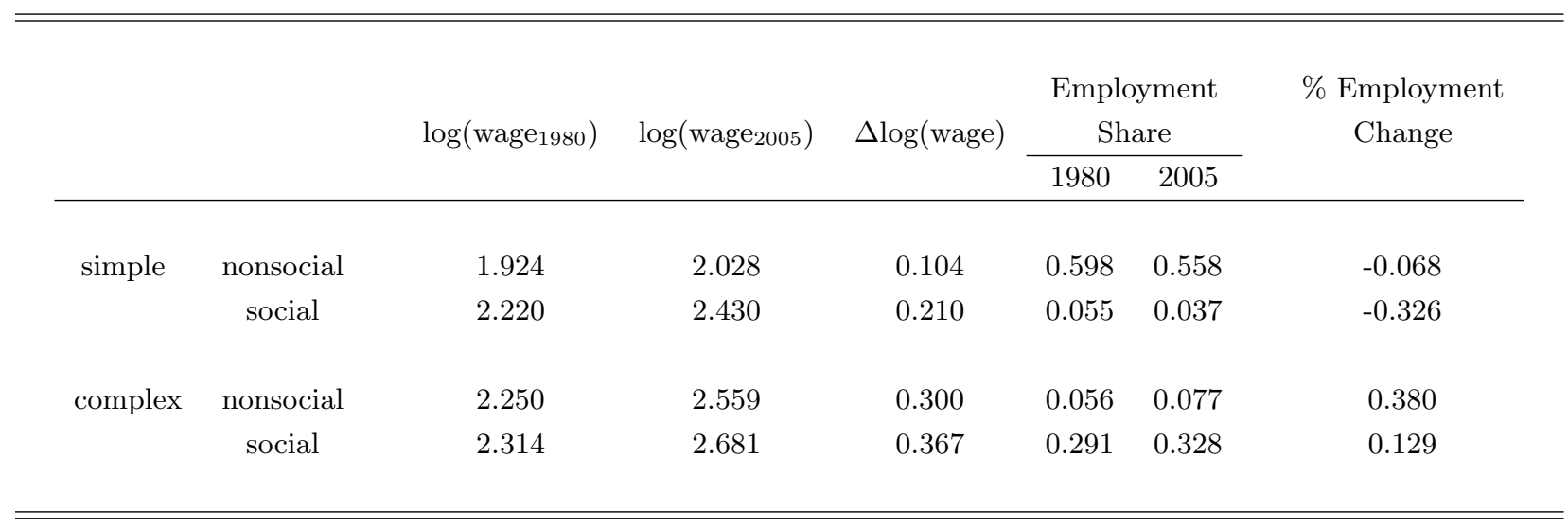

Notes: Wage and employment data is taken from the $19805 \%$ sample of the US Census and the 2005 ACS. The sample is restricted to non-institutionalized males aged 16-64 in the mainland United States. Complex occupations are defined as those whose complexity index is above the 66th percentile in the occupation-level complexity distribution. All other occupations are defined as simple. Social occupations are defined as those whose social skills index is above the 66th percentile in the occupation-level social skills distribution. All other occupations are defined as nonsocial.

growth is significantly higher for complex rather than simple occupations regardless of their social skill type. Second, the employment share of both complex-social and complex-nonsocial occupations increased between 1980 and 2005. At the same time, the employment share of both simple-social and simple-nonsocial occupations decreased. These results suggest that social skills principally contribute to higher wage and employment growth through their correlation with complexity.

Tables 12 and F.5 show results for the wage- and employment growth regressions when the social skill index is included as a control. In both tables we show results from our baseline occupationlevel regression (column i), from an occupation-level regression with demographic controls (column ii), and the group-level fixed effects regression specification (column iii). From Table 12 it can be seen that controlling for social skills does not substantially alter the coefficient estimates on complexity. Complex tasks remain significant predictors of 1980-2005 wage growth both in the occupation-level regressions (with or without control for occupational demographic means) and in the group-level fixed effect regression. The estimated coefficient on social skill intensity is positive and mostly significant as well, albeit smaller than the coefficients on task complexity. When it comes to employment growth neither social skill intensity nor task complexity are significant predictors of employment growth.

From this analysis we conclude that it is indeed possible to separately estimate the effects of complex task intensity and social skill intensity rather precisely. Given the results it is reasonable to conjecture that the two concepts are complementary. There is a substantial increase in the return to task complexity over and above the rise in the returns to social skills. Bringing together these two concepts to measuring occupational task content in a unified model of the occupational wage and employment structure is a promising avenue to pursue. 
Table 12: Wage Growth Regression with Social Skills

\begin{tabular}{|c|c|c|c|}
\hline Dependent Variable: & Change in Log & Jages 1980-2 & 005 \\
\hline \multicolumn{4}{|l|}{ Independent } \\
\hline Variable & (i) & (ii) & (iii) \\
\hline Complexity Index & $\begin{array}{c}0.427^{* * *} \\
(6.63)\end{array}$ & $\begin{array}{c}0.277^{* * *} \\
(3.82)\end{array}$ & $\begin{array}{c}0.279 * * * \\
(4.54)\end{array}$ \\
\hline Routine Index & $\begin{array}{c}0.0316 \\
(1.03)\end{array}$ & $\begin{array}{c}0.0409 \\
(1.27)\end{array}$ & $\begin{array}{c}0.0488 \\
(1.60)\end{array}$ \\
\hline Social Skill & $\begin{array}{c}0.164^{* * *} \\
(2.65)\end{array}$ & $\begin{array}{c}0.110^{*} \\
(1.73)\end{array}$ & $\begin{array}{c}0.0752 \\
(1.45)\end{array}$ \\
\hline Controls & None & $\begin{array}{c}\text { Occ Dem } \\
\text { Means }\end{array}$ & $\begin{array}{c}\text { Group } \\
\text { Level }\end{array}$ \\
\hline Order of 1980 Wage Poly. & 3 & 3 & 3 \\
\hline$N$ & 310 & 310 & 15142 \\
\hline
\end{tabular}

Notes: t-statistics are in parentheses. Significance levels are: ${ }^{* * *} 1 \%,{ }^{* *} 5 \%,{ }^{*} 10 \%$.

(i) occupation-level regression.

(ii) occupation-level regression with the following demographic controls: share of workers in an occupation with a college/high-school degree, share of workers in an occupation who are non-white, share of workers in an occupation who are married, share of female workers in an occupation, mean age of worker in an occupation, and mean number of children of workers in an occupation.

(iii) group-level regression on occupation $\times$ gender $\times$ education $\times$ race $\times$ age cells (see section 3.2 for discussion). Regressions include gender $\times$ education $\times$ race $\times$ age fixed effects.

Standard errors clustered at the occupation level.

\section{Conclusion}

This paper studies the relationship between task complexity and the occupational wage- and employment structure. Using $\mathrm{O}^{*} \mathrm{NET}$ data, we provide a novel characterization of occupations based on the extent to which they rely on complex tasks - tasks that require higher-order skills, such as the ability to abstract, solve problems, make decisions, or communicate effectively. We argue that this classification is insightful for understanding the wage structure in the cross-section as well as the observed wage and employment growth in the U.S. over the 1980-2005 time period. In particular, we document the following facts that are robust to the inclusion of a detailed set of controls, subsamples, and levels of aggregation. First, there is a positive relationship at the occupational level between task complexity and wage levels and wage growth. Second, in contrast 
with the literature studying RTBC, we show that, conditional on task complexity, routine-intensity of an occupation is not a significant predictor of wage levels and wage growth. Third, labor has reallocated from occupations with lower complexity towards occupations with higher complexity over this period. Fourth, within groups of occupations with similar task complexity labor has reallocated to non-routine occupations over this period.

We then formulate a model of Complex-Task Biased Technological Change with heterogeneous skills in performing complex tasks and show analytically that it can rationalize these facts. Two major conclusions emerge from our model. First, amongst the simple occupations, non-routine and routine jobs draw from the same pool of labor supply. As a result, wages are equalized across non-routine and routine occupations, conditional on an appropriate measure of skill complexity. This implies that non-routine work, such as low skill service jobs, are not shielded from the effects of automatization and computer adoption. Second, the strength of wage effects from technological change relative to employment effects is consistent with a heavily skewed distribution of skills for performing complex tasks. In particular, the model implies that this distribution should have a large mass at its lower tail. A result of this is that complex-task biased technological change can generate a situation in which a substantial share of the population is permanently trapped in low-paying jobs. 


\section{References}

Autor, D. H., Acemoglu, D., 2011. Skills, Tasks and Technologies: Implications for Employment and Earnings. In: Ashenfelter, O., Card, D. (Eds.), Handbook of Labor Economics. Vol. 4. Elsevier, pp. 1043-1171.

Autor, D. H., Dorn, D., 2013. The Growth of Low-Skill Service Jobs and the Polarization of the US Labor Market. American Economic Review 103 (5), 1553-1597.

Autor, D. H., Katz, L. F., Kearney, M. S., May 2006. Measuring and Interpreting Trends in Economic Inequality. AEA Papers and Proceedings 96 (2), 189-194.

Autor, D. H., Katz, L. F., Kearney, M. S., May 2008. Trends in US Wage Inequality: Revising the Revisionists. The Review of Economics and Statistics 90 (2), 300-323.

Autor, D. H., Levy, F., Murnane, R. J., 2003. The Skill Content of Recent Technological Change: An Empirical Exploration. Quarterly Journal Economics 118 (4), 1279-1333.

Bacolod, M. P., Blum, B. S., 2010. Two Sides of the Same Coin: "Residual" Inequality and the Gender Gap. Journal of Human Resources 45 (1), 197-242.

Beaudry, P., Green, D. A., Sand, B. M., 2016. The Great Reversal in the Demand for Skill and Cognitive Tasks. Journal of Labor Economics 34 (1), S199-S247.

Caines, C., Hofmann, F., Kambourov, G., 2016. Training Programs, Skills, and Human Capital: A Life-Cycle Approach, Working Paper.

Deming, D. J., 2015. The Growing Importance of Social Skills in the Labor Market, NBER Working Paper No. 21473.

Dustmann, C., Ludsteck, J., Schoenberg, U., 2009. Revisiting the German Wage Structure. The Quarterly Journal of Economics 124 (2), 843-881.

Firpo, S., Fortin, N. M., Lemieux, T., 2011. Occupational Tasks and Changes in the Wage Structure, IZA Discussion Paper No. 5542.

Goos, M., Manning, A., Salomons, A., May 2009. Job Polarization in Europe. American Economic Review 99 (2), 58-63.

Goos, M., Manning, A., Salomons, A., 2014. Explaining Job Polarization: Routine-Biased Technological Change and Offshoring. American Economic Review 104 (8), 2509-2526.

Green, D. A., Sand, B., 2014. Has the Canadian Labour Market Polarized?, Canadian Labour Market and Skills Researcher Network Working Paper No. 133. 
Kambourov, G., Manovskii, I., 2008. Rising Occupational and Industry Mobility in the United States: 1968-1997. International Economic Review 49 (1), 41-79.

Kambourov, G., Manovskii, I., 2009a. Occupational Mobility and Wage Inequality. Review of Economic Studies 76 (2), 731-759.

Kambourov, G., Manovskii, I., 2009b. Occupational Specificity of Human Capital. International Economic Review 50 (1), 63-115.

Katz, L. F., 2014. America's Job Challenges and the Continuing Role of the U.S. Department of Labor. Industrial Labor Relations Review 67, 578-583.

Krusell, P., Ohanian, L. E., Rios-Rull, J.-V., Violante, G. L., 2000. Capital-Skill Complementarity and Inequality: A Macroeconomic Analysis. Econometrica 68 (5), 1029-1053.

Ross, M. B., 2015. Skill Biased Technical Change: Panel Evidence of Task Orientation and Wage Effects, University of Connecticut Working Paper.

Yamaguchi, S., 2012. Tasks and Heterogeneous Human Capital. Journal of Labor Economics 30 (1), $1-53$. 


\section{APPENDICES}

\section{A Principal Components Analysis}

Under the PCA, the complexity score for occupation $o, C_{0}$, is equivalent to

$$
C_{o}=\gamma \cdot X_{o}
$$

where $\gamma$ is a $1 \times 35$ vector of factor loadings and $X_{o}$ is a $35 \times 1$ vector of the selected $\mathrm{O}^{*} \mathrm{NET}$ descriptors. The factor loadings are chosen so that $C_{o}$ captures as much of the variance in $X_{o}$ as possible. To be precise, $\gamma$ is set so that

$$
\begin{aligned}
\gamma & =\underset{\gamma}{\operatorname{argmin}} \sum_{o}\left\|X_{o}-C_{o} \cdot \gamma^{\prime}\right\| \\
& =\underset{\gamma}{\operatorname{argmin}} \sum_{o}\left\|X_{o}-\gamma \cdot X_{o} \cdot \gamma^{\prime}\right\| .
\end{aligned}
$$

The factor loadings are computed using O*NET information on 315 occupations. ${ }^{21}$ When computing $\gamma$ we weight the occupations by their employment shares in 1980, which we compute from a 5 percent sample of the 1980 US Census. ${ }^{22}$ The estimated factor loadings can be seen in Table A.1. The complexity index that we use in our empirical analysis are the imputed complexity scores $C_{o}$ converted to percentile rankings between 0 and 1, using as weights the relative employment shares of each occupation. Appendix D lists both the weighted and the raw complexity indices for the complete set of occupations in our sample. ${ }^{23}$

\footnotetext{
${ }^{21}$ See footnote 12 in the text.

${ }^{22}$ The sample is non-institutionalized non-farm males aged 16 to 64 in the mainland United States.

${ }^{23}$ The weighted and raw complexity indices including the agricultural occupations are available upon request.
} 
Table A.1: O*NET Questions and PCA Factor Loadings

\begin{tabular}{|c|c|}
\hline Descriptor & Factor Loading \\
\hline \multicolumn{2}{|l|}{ O*NET Worker Abilities } \\
\hline Oral Comprehension & 0.1818 \\
\hline Written Comprehension & 0.1848 \\
\hline Written Expression & 0.1797 \\
\hline Fluency of Ideas & 0.1813 \\
\hline Originality & 0.1772 \\
\hline Problem Sensitivity & 0.1799 \\
\hline Deductive Reasoning & 0.1870 \\
\hline Inductive Reasoning & 0.1814 \\
\hline Information Ordering & 0.1761 \\
\hline Category Flexibility & 0.1734 \\
\hline Mathematical Reasoning & 0.1702 \\
\hline Category Flexibility & 0.1734 \\
\hline Number Facility & 0.1640 \\
\hline Memorization & 0.1688 \\
\hline Speed of Closure & 0.1629 \\
\hline Flexibility of Closure & 0.1407 \\
\hline Perceptual Speed & 0.0796 \\
\hline \multicolumn{2}{|l|}{ O*NET Skills } \\
\hline Mathematics & 0.1589 \\
\hline Science & 0.1402 \\
\hline Critical Thinking & 0.1835 \\
\hline Active Learning & 0.1859 \\
\hline Complex Problem Solving & 0.1867 \\
\hline Programming & 0.1400 \\
\hline Judgement and Decision Making & 0.1862 \\
\hline Systems Analysis & 0.1832 \\
\hline Systems Evaluation & 0.1847 \\
\hline \multicolumn{2}{|l|}{$\mathrm{O}^{*} \mathrm{NET}$ Activities } \\
\hline Monitor Processes, Materials or Surroundings & 0.1106 \\
\hline Judging the Qualities of Things/Services/People & 0.1520 \\
\hline Processing Information & 0.1712 \\
\hline Evaluating Information to Determine Compliance with Standards & 0.1493 \\
\hline Analyzing Data or Information & 0.1807 \\
\hline Making Decisions and Solving Problems & 0.1774 \\
\hline Thinking Creatively & 0.1647 \\
\hline Updating and Using Relevant Information & 0.1761 \\
\hline Developing Objectives and Strategies & 0.1662 \\
\hline
\end{tabular}




\section{B Model}

Given full depreciation of capital, the social planner maximizes output. Define $B=c_{m}^{\beta}$. The maximization problem is:

$$
\begin{aligned}
& \max _{K, K_{c}, c^{T}, S_{R}}\left\{\left(y_{s}\right)^{\gamma} \cdot\left(y_{c}\right)^{1-\gamma}-\pi_{K} \cdot K\right\} \\
\text { subject to } & : \\
y_{s} & =\left[\left(y_{R}\right)^{\mu}+\left(y_{N R}\right)^{\mu}\right]^{\frac{1}{\mu}} \\
y_{c} & =\left(\alpha_{c} \cdot C\right)^{\rho} \cdot\left(\alpha_{k, c} \cdot K_{c}\right)^{1-\rho} \\
y_{N R} & =S_{N R} \\
y_{R} & =\left[\alpha_{s, R} \cdot S_{R}^{\psi}+\alpha_{k, R} \cdot K_{R}^{\psi}\right]^{\frac{1}{\psi}} \\
C & =\int_{c^{T}}^{\infty} c \cdot d G(c)=\left(\frac{\beta}{\beta-1}\right) \cdot B \cdot\left(c^{T}\right)^{1-\beta} \\
S_{N R} & =G\left(c^{T}\right)-S_{R}=1-B \cdot\left(c^{T}\right)^{-\beta}-S_{R} \\
K & =K_{c}+K_{R} .
\end{aligned}
$$

Notice that we have normalized $\alpha_{s, N R}=1$ so that all factor productivity parameters are relative to the factor productivity of labor inputs in the non-routine process. Expressions for relative wages can then be derived from the firms' profit maximization problems.

\section{Proof of Proposition}

In the following it is convenient to define

$$
k_{R} \equiv \frac{K_{R}}{S_{R}} \quad \text { and } \quad \widetilde{y}_{S}=\frac{y_{S}}{S_{N R}} .
$$

From the first-order condition for $c^{T}, \gamma=.5$, and the expression for $C$ in terms of $c^{T}$ :

$$
c^{T}=\left[\left(\frac{\beta-1}{\beta \cdot B}\right) \cdot \rho \cdot S_{N R} \cdot\left(\widetilde{y}_{S}\right)^{\mu}\right]^{-\frac{1}{\beta}} .
$$

Substituting this back into $C$ yields

$$
C=\left(\frac{\beta \cdot B}{\beta-1}\right)^{\frac{1}{\beta}} \cdot\left[\rho \cdot S_{N R} \cdot\left(\widetilde{y}_{S}\right)^{\mu}\right]^{\frac{\beta-1}{\beta}} .
$$

The first-order condition for $S_{R}$ is

$$
\alpha_{s, R} \cdot\left(S_{N R}\right)^{1-\mu} \cdot\left(S_{R}\right)^{\psi-1} \cdot\left(y_{R}\right)^{\mu-\psi}=1,
$$

and the first-order conditions for the two types of capital are

$$
\begin{aligned}
Y & =\left(\frac{\pi_{K}}{\alpha_{k, R} \cdot \gamma}\right) \cdot\left(y_{S}\right)^{\mu} \cdot\left(y_{R}\right)^{\psi-\mu} \cdot\left(K_{R}\right)^{1-\psi} \\
K_{c} & =\left(\frac{(1-\gamma) \cdot(1-\rho)}{\pi_{K}}\right) \cdot Y .
\end{aligned}
$$


We can now combine the two conditions for the capital inputs to get:

$$
K_{c}=\left(\frac{1-\rho}{\alpha_{k, R}}\right) \cdot\left(y_{S}\right)^{\mu} \cdot\left(y_{R}\right)^{\psi-\mu} \cdot\left(K_{R}\right)^{1-\psi} .
$$

From the first-order condition for $S_{R}$, rewrite equation (C.4) as

$$
Y=\left(\frac{\pi_{K}}{\gamma}\right) \cdot\left(\frac{\alpha_{s, R}}{\alpha_{k, R}}\right) \cdot\left(\widetilde{y}_{S}\right)^{\mu} \cdot S_{N R} \cdot\left(k_{R}\right)^{1-\psi}
$$

and equation (C.5) as

$$
K_{c}=(1-\rho) \cdot\left(\frac{\alpha_{s, R}}{\alpha_{k, R}}\right) \cdot\left(\widetilde{y}_{S}\right)^{\mu} \cdot S_{N R} \cdot\left(k_{R}\right)^{1-\psi} .
$$

Next, evaluate the aggregate production function at the expressions for $C$ and $K_{c}$ derived above:

$$
Y=A_{1} \cdot\left(S_{N R}\right)^{\gamma} \cdot\left(\left(\widetilde{y}_{S}\right)^{\mu}\right)^{\frac{\gamma}{\mu}} \cdot\left[\left(\widetilde{y}_{S}\right)^{\mu} \cdot S_{N R}\right]^{\left(\frac{\beta-1}{\beta}\right) \cdot \rho \cdot(1-\gamma)} \cdot\left[\left(\widetilde{y}_{s}\right)^{\mu} \cdot S_{N R} \cdot\left(k_{R}\right)^{1-\psi}\right]^{(1-\rho) \cdot(1-\gamma)},
$$

where

$$
A_{1}=\left[\rho^{\frac{\beta-1}{\beta}}\left(\frac{\beta \cdot B}{\beta-1}\right)^{\frac{1}{\beta}} \cdot \alpha_{c}\right]^{\rho \cdot(1-\gamma)} \cdot\left[(1-\rho) \cdot\left(\frac{\alpha_{s, R}}{\alpha_{k, R}}\right) \cdot \alpha_{k, c}\right]^{(1-\rho) \cdot(1-\gamma)} .
$$

Combining this equation with (C.6) and collecting terms yields

$$
A_{2} \cdot\left[\left(k_{R}\right)^{1-\psi}\right]^{\lambda_{k}} \cdot\left[S_{N R}\right]^{\lambda_{S}}=\left[\left(\widetilde{y}_{s}\right)^{\mu}\right]^{\lambda_{y}},
$$

with

$$
\begin{aligned}
& A_{2}=\left(\frac{\pi_{K}}{\gamma}\right) \cdot\left(\frac{\alpha_{s, R}}{\alpha_{k, R}}\right)^{1-(1-\rho) \cdot(1-\gamma)} \cdot\left[\rho^{\frac{\beta-1}{\beta}}\left(\frac{\beta \cdot B}{\beta-1}\right)^{\frac{1}{\beta}} \cdot \alpha_{c}\right]^{-\rho \cdot(1-\gamma)} \cdot\left[(1-\rho) \cdot \alpha_{k, c}\right]^{-(1-\rho) \cdot(1-\gamma)} \\
& \lambda_{k}=1-(1-\rho) \cdot(1-\gamma)>0 \\
& \lambda_{S}=\rho \cdot\left(\frac{1-\gamma}{\beta}\right)>0 \\
& \lambda_{y}=\gamma \cdot\left(\frac{1-\mu}{\mu}\right)-\rho \cdot\left(\frac{1-\gamma}{\beta}\right) .
\end{aligned}
$$

As it turns out, equilibrium does not have an analytical solution. Rather, we will characterize the equilibrium using two equations in the two unknowns $\left(S_{N R}, S_{R}\right)$ and then state several comparative statics results from implicit differentiation. The first equation is given by (C.8), which was derived above from first-order conditions and the assumptions on technologies. The second equation relies on the labor market equilibrium condition.

Define $\widetilde{s}=\frac{S_{N R}}{S_{R}}$ and express the production technology $y_{s}$ as

$$
\left(\widetilde{y}_{S}\right)^{\mu}=\left(\frac{y_{R}}{S_{N R}}\right)^{\mu}+1
$$


The first-order condition for $S_{R}$ in equation (C.3) can be used to show that

$$
\left(\frac{y_{R}}{S_{N R}}\right)=\left(\alpha_{s, R}\right)^{\frac{1}{\psi-\mu}} \cdot(\widetilde{s})^{\frac{1-\psi}{\psi-\mu}}
$$

Combining these two equations we get

$$
\left(\widetilde{y}_{S}\right)^{\mu}=\left(\alpha_{s, R}\right)^{\frac{\mu}{\psi-\mu}} \cdot(\widetilde{s})^{\mu \cdot\left(\frac{1-\psi}{\psi-\mu}\right)}+1
$$

Here we substituted out $\frac{y_{R}}{S_{N R}}$. Plug the technology for $y_{R}$ into (C.11) we can derive an expression for $k_{R}$ in terms of $\widetilde{s}$ :

$$
k_{R}=\left[\left(\frac{\alpha_{s, R}}{\alpha_{k, R}}\right) \cdot\left(\left(\alpha_{s, R}\right)^{\frac{\mu}{\psi-\mu}} \cdot(\widetilde{s})^{\psi \cdot\left(\frac{1-\mu}{\psi-\mu}\right)}-1\right)\right]^{\frac{1}{\psi}} .
$$

Differentiating (C.11) and (C.13) with respect to $S_{N R}$ and $S_{R}$ yields

$$
\begin{aligned}
\frac{\partial\left(\widetilde{y}_{S}\right)^{\mu}}{\partial S_{N R}} & =\left(\alpha_{s, R}\right)^{\frac{\mu}{\psi-\mu}} \cdot \mu \cdot\left(\frac{1-\psi}{\psi-\mu}\right) \cdot(\widetilde{s})^{\mu \cdot\left(\frac{1-\psi}{\psi-\mu}\right)} \cdot\left(\widetilde{s} \cdot S_{R}\right)^{-1} \\
\frac{\partial\left(\widetilde{y}_{S}\right)^{\mu}}{\partial S_{R}} & =-\frac{\partial\left(\widetilde{y}_{S}\right)^{\mu}}{\partial S_{N R}} \cdot \widetilde{s} \\
\frac{\partial k_{R}}{\partial S_{N R}} & =\frac{1}{\psi} \cdot k_{R}^{1-\psi} \cdot\left(\frac{\alpha_{s, R}}{\alpha_{k, R}}\right) \cdot\left(\alpha_{s, R}\right)^{\frac{\mu}{\psi-\mu}} \cdot \psi \cdot\left(\frac{1-\mu}{\psi-\mu}\right) \cdot(\widetilde{s})^{\psi \cdot\left(\frac{1-\mu}{\psi-\mu}\right)} \cdot\left(\widetilde{s} \cdot S_{R}\right)^{-1} \\
\frac{\partial k_{R}}{\partial S_{R}} & =-\frac{\partial k_{R}}{\partial S_{N R}} \cdot \widetilde{s} .
\end{aligned}
$$

Total differentiation of (C.8) with respect to $S_{N R}$ and $S_{R}$ yields:

$$
\begin{aligned}
& A_{2} \cdot\left(S_{N R}\right)^{\lambda_{S}} \cdot\left(k_{R}\right)^{(1-\psi) \cdot \lambda_{k}} \cdot\left[\left(\frac{\lambda_{S}}{S_{N R}}\right) d S_{N R}+\left(\frac{(1-\psi) \cdot \lambda_{k}}{k_{R}}\right) \cdot\left[\left(\frac{\partial k_{R}}{\partial S_{N R}}\right) d S_{N R}-\left(\frac{\partial k_{R}}{\partial S_{N R}} \cdot \widetilde{s}\right) d S_{R}\right]\right] \\
= & \lambda_{y} \cdot\left[\left(\widetilde{y}_{s}\right)^{\mu}\right]^{\lambda_{y}-1} \cdot\left[\left(\frac{\partial\left(\widetilde{y}_{S}\right)^{\mu}}{\partial S_{N R}}\right) d S_{N R}-\left(\frac{\partial\left(\widetilde{y}_{S}\right)^{\mu}}{\partial S_{N R}} \cdot \widetilde{s}\right) d S_{R}\right] .
\end{aligned}
$$

Bringing all terms involving $d S_{N R}$ to the left-hand side and all terms involving $d S_{R}$ on the righthand side clarifies that $\frac{\partial k_{R}}{\partial S_{N R}}$ enters both terms positively and $\lambda_{y} \cdot \frac{\partial\left(\widetilde{y}_{S}\right)^{\mu}}{\partial S_{N R}}$ negatively. Noting that the solution of the social planners' problem will be interior because the technologies for $\left(Y, y_{s}, y_{c}, y_{R}\right)$ satisfy Inada conditions and that $\frac{\partial k_{R}}{\partial S_{N R}}$ and $\frac{\partial\left(\widetilde{y}_{S}\right)^{\mu}}{\partial S_{N R}}$ have the same sign we get

$$
\frac{d S_{N R}}{d S_{R}}>0 \text { if } \frac{\partial k_{R}}{\partial S_{N R}}>0 \text { and } \lambda_{y}<0 .
$$

These conditions are satisfied if $\psi>\mu$ and $\mu>\mu^{*}$, where $\mu^{*}=\frac{\beta}{(\beta+\rho)}$.

It is important to note that this is a property of equilibrium, even though we have not used the aggregate resource constraint for labor inputs yet. The latter merely pins down the level of $S_{R}$ (or $S_{N R}$ ), while (C.8) determines implicitly the equilibrium relationship between $S_{N R}$ and $S_{R}$.

Next, use the labor market resource constraint $S_{N R}=1-B \cdot\left(c^{T}\right)^{-\beta}-S_{R}$ together with (C.1):

$$
\left(\frac{S_{N R}}{S_{R}}\right) \cdot\left[1+\left(\frac{\beta-1}{\beta}\right) \cdot \rho \cdot\left(\left(\alpha_{s, R}\right)^{\frac{\mu}{\psi-\mu}} \cdot(\widetilde{s})^{\mu \cdot\left(\frac{1-\psi}{\psi-\mu}\right)}+1\right)\right]=\frac{1}{S_{R}}-1 .
$$


This equation can be rearranged to express the term in square brackets as $\frac{1-S_{R}}{S_{N R}}$. Totally differentiating it with respect to $\widetilde{s}$ and $S_{R}$ yields

$$
\left(\frac{1-S_{R}}{S_{N R}}\right) d \widetilde{s}+\left(\widetilde{s} \cdot \mu \cdot\left(\frac{1-\psi}{\psi-\mu}\right) \cdot\left(\frac{\beta-1}{\beta}\right) \cdot \rho \cdot\left(\alpha_{s, R}\right)^{\frac{\mu}{\psi-\mu}} \cdot \widetilde{s}^{\mu \cdot\left(\frac{1-\psi}{\psi-\mu}\right)-1}\right) d \widetilde{s}=-\left(\frac{1}{S_{R}}\right)^{2} d S_{R} .
$$

Now notice that the terms multiplying $d \widetilde{s}$ add up easily since $\widetilde{s} \cdot \widetilde{s}^{\mu \cdot\left(\frac{1-\psi}{\psi-\mu}\right)-1}=\widetilde{s}^{\mu \cdot\left(\frac{1-\psi}{\psi-\mu}\right)}$, which is exactly how $\widetilde{s}$ shows up in the term $\left(\frac{1-S_{R}}{S_{N R}}\right)$. In particular,

$$
\begin{aligned}
& \left(\frac{1-S_{R}}{S_{N R}}\right)+\mu \cdot\left(\frac{1-\psi}{\psi-\mu}\right) \cdot\left(\frac{\beta-1}{\beta}\right) \cdot \rho \cdot\left(\alpha_{s, R}\right)^{\frac{\mu}{\psi-\mu}} \cdot \widetilde{s}^{\mu \cdot\left(\frac{1-\psi}{\psi-\mu}\right)} \\
= & 1+\left(\frac{\beta-1}{\beta}\right) \cdot \rho \cdot\left[1+\frac{\psi \cdot(1-\mu)}{\psi-\mu} \cdot\left(\alpha_{s, R}\right)^{\frac{\mu}{\psi-\mu}} \cdot(\widetilde{s})^{\mu \cdot\left(\frac{1-\psi}{\psi-\mu}\right)}\right] .
\end{aligned}
$$

A sufficient condition for this term to be positive is $\psi>\mu$. In this case we have

$$
\frac{d \widetilde{s}}{d S_{R}}<0
$$

We thus find that if $\psi>\mu$, then the labor share of non-routine labor in the simple production processes decreases if $S_{R}$ increases.

To complete the characterization of the equilibrium labor allocation, we derive comparative statics results for $\widetilde{s}$ in terms of model parameters. First rewrite equation (C.8) using (C.12) and (C.13) and the definition of $A_{2}$ as

$$
\left(\left(\alpha_{s, R}\right)^{\frac{\mu}{\psi-\mu}} \cdot(\widetilde{s})^{\psi \cdot\left(\frac{1-\mu}{\psi-\mu}\right)}-1\right)^{\frac{(1-\psi)}{\psi} \cdot \lambda_{k}} \cdot\left(S_{N R}\right)^{\lambda_{S}} \cdot\left(\left(\alpha_{s, R}\right)^{\frac{\mu}{\psi-\mu}} \cdot(\widetilde{s})^{\mu \cdot\left(\frac{1-\psi}{\psi-\mu}\right)}+1\right)^{-\lambda_{y}}=A_{3},
$$

where

$$
A_{3}=\left(\frac{\gamma}{\pi_{K}}\right) \cdot\left(\frac{\alpha_{k, R}}{\alpha_{s, R}}\right)^{\frac{\lambda_{k}}{\psi}} \cdot\left[\rho^{\frac{\beta-1}{\beta}}\left(\frac{\beta \cdot B}{\beta-1}\right)^{\frac{1}{\beta}} \cdot \alpha_{c}\right]^{\rho \cdot(1-\gamma)} \cdot\left[(1-\rho) \cdot \alpha_{k, c}\right]^{(1-\rho) \cdot(1-\gamma)} .
$$

Let $S_{N R}=h\left(\widetilde{s} \mid \alpha_{s, R}, \beta, \mu, \psi, \rho\right)$ be the function defined implicitly by (C.17), with $h^{\prime}\left(\widetilde{s} \mid \alpha_{s, R}, \beta, \mu, \psi, \rho\right)$ as defined above. Also define $L H S$ as the left-hand side of (C.20). Let $x$ stand for any of the parameters entering $A_{3}$ but not $L H S$. These are $\pi_{K},\left(\frac{\alpha_{k, R}}{\alpha_{s, R}}\right), \alpha_{c}, \alpha_{k, c}$. Then we get:

$$
\frac{d \widetilde{s}}{d x}=\frac{\frac{\partial A_{3}}{\partial x}}{\frac{\partial L H S}{\partial \widetilde{s}}} .
$$

If $\psi>\mu$ and $\mu>\mu^{*}$, then $\lambda_{y}<0$ and it is straightforward to show that $\frac{\partial L H S}{\partial \widetilde{s}}>0$. Hence, $\frac{d \widetilde{s}}{d x}$ has the same sign as $\frac{\partial A_{3}}{\partial x}$ under these assumptions. This establishes the comparative statics results in the proposition regarding employment. In particular, any exogenous force that increases $\widetilde{s}$ comes with a decline in both $S_{R}$ and $S_{N R}$. 
Moving on to characterizing prices, we use the fact that all marginal revenue products need to be equal to marginal costs. For the three intermediate input prices we thus get

$$
\begin{aligned}
p_{R} & =\gamma \cdot\left(\frac{Y}{y_{s}}\right) \cdot\left(\frac{y_{s}}{y_{R}}\right)^{1-\mu} \\
p_{N R} & =\gamma \cdot\left(\frac{Y}{y_{s}}\right) \cdot\left(\frac{y_{s}}{S_{N R}}\right)^{1-\mu} \\
p_{c} & =(1-\gamma) \cdot\left(\frac{Y}{y_{c}}\right)
\end{aligned}
$$

and for wages we have

$$
\begin{aligned}
w_{N R} & =p_{N R} \\
w_{R} & =p_{R} \cdot \alpha_{s, R} \cdot\left(\frac{y_{R}}{S_{R}}\right)^{1-\psi} \\
w_{c} & =p_{c} \cdot \rho \cdot \frac{y_{c}}{C} .
\end{aligned}
$$

Furthermore, in equilibrium it must be the case that

$$
w_{N R}=w_{R} \Leftrightarrow w_{R}=p_{N R} .
$$

Equations (C.24) and (C.27) imply that

$$
w_{c}=\rho \cdot(1-\gamma) \cdot\left(\frac{Y}{C}\right)
$$

and equations (C.22) and (C.26) yield

$$
w_{R}=\gamma \cdot \alpha_{s, R} \cdot Y \cdot y_{s}^{-\mu} \cdot y_{R}^{\mu-\psi} \cdot S_{R}^{\psi-1}
$$

The first-order condition for $S_{R}$ from the social planner's problem can be used to write

$$
w_{R}=\gamma \cdot Y \cdot \widetilde{y}_{s}^{-\mu} \cdot S_{N R}^{-1}
$$

The first-order condition for $c^{T}$ from the social planner's problem combined with equations (C.28) and (C.29) implies that

$$
\frac{w_{c}}{w_{R}}=\frac{1}{c^{T}} .
$$

Combining this equation with equation (7) yields

$$
C^{*}=\left(\frac{\beta}{\beta-1}\right) \cdot c_{m}^{\beta} \cdot\left(\frac{w_{c}}{w_{R}}\right)^{\beta-1},
$$

From above we know that

$$
\frac{d S_{R}}{d x}<0, \frac{d S_{N R}}{d x}<0
$$


The labor market equilibrium condition then implies that

$$
\frac{d C}{d x}>0 .
$$

Since $\beta>1$ this is only possible if

$$
\frac{d c^{T}}{d x}<0
$$

characterizing our equilibrium result. In particular,

$$
\frac{d \frac{w_{c}}{w_{R}}}{d x}>0
$$


"COMPLEX-TASK BIASED TECHNOLOGICAL CHANGE

AND THE LABOR MARKET"

COLIN CAINES, FLORIAN HOFFMANN, AND GUEORGUI KAMBOUROV

ONLINE APPENDICES: NOT FOR PUBLICATION

\section{Complexity Percentiles of Occupations}

Occupation List and Complexity Percentile

\begin{tabular}{|c|c|c|}
\hline Occupation & Complexity Index, Weighted & Complexity Index, Raw \\
\hline Vehicle washers and equipment cleaners & .0016101 & 0 \\
\hline Clothing pressing machine operators & .0019852 & .0474957 \\
\hline Food preparation workers & .0022551 & .058032 \\
\hline Janitors & .0249187 & .0918971 \\
\hline Shoemakers, other prec. apparel and fabric workers & .0252782 & .0925525 \\
\hline Housekeepers, maids, butlers, and cleaners & .02768 & .1111131 \\
\hline Crossing guards & .027743 & .1378214 \\
\hline Butchers and meat cutters & .032228 & .1428061 \\
\hline Washing, cleaning, and pickling machine operators & .0323416 & .1434333 \\
\hline Knitters, loopers, and toppers textile operatives & .0328108 & .1472788 \\
\hline Laundry and dry cleaning workers & .0338383 & .1492647 \\
\hline Sales demonstrators, promoters, and models & .033879 & .156003 \\
\hline Waiters and waitresses & .0361711 & .1564893 \\
\hline Ushers & .0362983 & .1573397 \\
\hline Packers and packagers by hand & .0393966 & .158118 \\
\hline Molders and casting machine operators & .0412176 & .1644148 \\
\hline Paperhangers & .0414369 & .1648163 \\
\hline Textile sewing machine operators & .0422301 & .1682662 \\
\hline Miscellanious food preparation and service workers & .0467314 & .1775591 \\
\hline Garbage and recyclable material collectors & .0478686 & .1876843 \\
\hline Mail carriers for postal service & .0521171 & .197245 \\
\hline Metal platers & .0528155 & .1987244 \\
\hline Mail and paper handlers & .0528622 & .1993897 \\
\hline Production helpers & .0543581 & .2025392 \\
\hline Parking lot attendants & .0547438 & .2062236 \\
\hline
\end{tabular}


Cashiers

Furnance, kiln, and oven operators, apart from food 
Office machine operators, n.e.c. 
Administrative support jobs, n.e.c.

Other metal and plastic workers

Locksmiths and safe repairers

Pest control occupations

Secretaries and stenographers

Cabinetmakers and bench carpeters

Grinding, abrading, buffing, and polishing workers

Rollers, roll hands, and finishers of metal

Health and nursing aides

Repairers of data processing equipment

Musicians and composers

Precision grinders and fitters

Legal assistants and paralegals

Public transportation attendants and inspectors

Precision makers, repairers, and smiths

Child care workers

Protective service, n.e.c.

Sheriffs, bailiffs, correctional institution officers

Human resources clerks, excl payroll and timekeeping

Shipping and receiving clerks

Bus, truck, and stationary engine mechanics

Bill and account collectors

Eligibility clerks for government prog., social welfare

Retail salespersons and sales clerks

Dental Assistants

Drillers of oil wells

Repairers of household appliances and power tools

Railroad conductors and yardmasters

Records clerks

Transportation ticket and reservation agents

Boilermakers

Machinists

Guards and police, except public service

Bookkeepers and accounting and auditing clerks

Announcers

Telecom and line installers and repairers

Separating, filtering, and clarifying machine operators
.4148578

.399947

.4174884

.3999856

.4177947

.4042563

.4183996

.4078006

.4192881

.4078266

.4204831

.4087574

.424457

.4128952

.4247807

.4160658

.4280792

4171047

.4288996

.4171405

.4299978

.4204387

.4303453

.4211147

.4307436

.4226654

.4309823

.4237073

.4319676

.4237647

.4325137

.4243256

.4328654

.4262462

.435336

.4262941

.4354915

.4267306

.4447515

.428109

.4475912

.429

.4481743

.4299577

.4482474

.4325045

.4966205

.4343396

.496669

.4376354

.4981148

.4399363

.4995348

.4415153

.5005776

.443033

.5009044

.4443701

.5016944

.4447685

.5023338

.4487705

.5117255

.4497759

.5188752

.4504754

.5219113

.4512078

.5224794

.4535288

.5280938

.4583492

.529344 
Writers and authors

Editors and reporters

Drafters

Office supervisors

Insurance underwriters

Purchasing agents and buyers of farm products

Real estate sales occupations

Managers of properties and real estate

Radiologic technologists and technicians

Supervisors of construction work

Librarians

Programmers of numerically controlled machine tools

Miscellanious transportation occupations

Actors, directors, and producers

Construction inspectors

Sales supervisors and proprietors

Buyers, wholesale and retail trade

Primary school teachers

Power plant operators

Material recording, sched., prod., plan., expediting cl

Licensed practical nurses

Explosives workers

Teachers, n.e.c.

Police and detectives, public service

Special education teachers

Clinical laboratory technologies and technicians

Biological technicians

Health technologists and technicians, n.e.c.

Secondary school teachers

Archivists and curators

Computer and peripheral equipment operators

Therapists, n.e.c.

Occupational therapists

Technicians, n.e.c.

Other financial specialists

Clergy and religious workers

Respiratory therapists
.6394979

.5393205

.6413863

.5394176

.646362

.5413974

.6533478

.5456049

.65348

.546587

.6538292

.5466031

.6603308

.5472972

.662331

.5474688

.6628282

.5513899

.6775198

.5614792

.6779959

.5638413

.6781242

.5646561

.6782089

.565611

.6789458

.5667997

.6797738

.5677375

.7039372

.5694135

.7057255

.5711881

.7150567

.5715752

.7155595

.5721468

.7192039

.5773472

.7194566

.5794451

.5831427

.5840338

.7216645

.5924041

.5938933

.5957232

.6006724

.6040076

.6074831

.7401884

.6088821

.6090996

.6091286

.6093953

.6143714

.6215262

.7525147

.6251798

.7585013

.6283643 
Surveryors, cartographers, mapping scientists/techs 
Financial managers

.9610853

.738309

Sales engineers

.9619034

.7418968

Industrial engineers

.965312

.7441369

Optometrists

.9657143

.7482106

Atmospheric and space scientists

.9658464

.750657

Physical scientists, n.e.c.

.9659775

.7544398

Podiatrists

.9660975

.7555497

Economists, market and survey researchers

.9674464

.7582632

Architects

.9693015

.7646669

Petroleum, mining, and geological engineers

.9697799

.7699337

Psychologists

.9706449

.770106

Urban and regional planners

.9708155

.7740712

Agricultural and food scientists

.9711688

.7783705

Geologists

.9719127

.7851528

Chemists

.9734307

.7941574

Engineers and other professionals, n.e.c.

.9786969

.8180442

.9793075

.828075

.9830744

.8318534

Mechanical engineers

.9918112

.8355613

Civil engineers

.9955139

.8388404

Metallurgical and materials engineers

.9959559

.8439432

Aerospace engineers

.9975579

.8576173

Medical scientists

.9978017

.8673735

Actuaries

.9979488

.8832101

Biological scientists

.99853

.8882928

Chemical engineers

.9995857

.9360058 


\section{E Worker Sorting}

As discussed in Section 4, our model makes strong predictions about worker sorting. In the process of complex-task biased technological change the skill threshold that separates workers going to the complex occupations and those who do not falls. If there are observable worker characteristics that are correlated with the skill to solve complex tasks, then one may hope that one can test the prediction of a falling threshold. Unfortunately, with repeated cross-sectional data, this is difficult, for at least two reasons. First, a decrease in the skill threshold means that the average skill in either type of occupation falls. Second, observable characteristics that are likely to relate with the skill to solve complex tasks, such as educational attainment, have been subject to strong aggregate trends.

We construct a test of the sorting mechanism generated by our model that addresses both issues as follows. We use two measures of worker characteristics that are likely related to the skill for solving complex tasks. The first measure is the fraction of workers with some postsecondary education. This measure has the advantage that it is likely to be small in simple occupations and large in complex occupations. We thus expect a larger decrease of this measure in complex occupations, absent any aggregate trends in educational attainment. The second measure is the share of those with a high school degree. This measure has the advantage that individuals with a high school degree are most likely to be near the skill threshold that separates workers going to complex and simple occupations. To control for aggregate trends in educational attainment we compare the change in the share of the highly educated over the sample period between groups of simple and the complex occupations. This can be interpreted as the regression coefficient on the interaction of a complex occupation dummy and a time fixed effect in a difference-in-difference (DiD) regression.

This assumption is likely violated if one compares changes in the educational composition between all complex and simple occupations. Instead, we only compare workers in occupations near our exogenously set threshold for the task complexity defining complex occupations, which we have assumed to be either the 50th or the 66th percentile. More precisely, we compare the growth of our observed skill measures among those working in occupations between the 45th and 65th percentile and those in occupations between the 67 th and 87 th percentile of the complexity distribution. For robustness, we repeat the exercise using occupations between the 29 th and the 49th percentile on the one hand and the 51st and the 71st percentile on the other hand. Results are shown in Table E.1. We find that in accordance with our hypothesis, the share of both medium- and highly educated workers has grown faster in simple than complex occupations. One exception is the measure of highly educated when using the 50th percentile threshold. This may be the case because the demand for highly skilled individuals is too small in occupations below the 50th percentile to make a comparison with complex occupations meaningful. In particular, the common-trends assumption 
Table E.1: Change in Average Education Outcomes by Occupation

\begin{tabular}{|c|c|c|c|}
\hline & & $\begin{array}{c}\text { fraction with } \\
\text { postsecondary education }\end{array}$ & $\begin{array}{l}\text { fraction with } \\
\text { high school degree }\end{array}$ \\
\hline task complexity & $45-65$ & 0.141 & 0.125 \\
\hline percentile & $67-87$ & 0.063 & 0.059 \\
\hline task complexity & $29-49$ & 0.104 & 0.157 \\
\hline percentile & $51-71$ & 0.134 & 0.125 \\
\hline
\end{tabular}

Notes: The table reports changes in the share of workers with a postsecondary education or high school degree amongst occupations whose complexity index falls within the given percentiles in the occupation level distribution.

for the validity of the DiD design may be violated in this case. Overall, we conclude that in the aggregate the average skill of those going to complex occupations has decreased, consistent with Beaudry et al. (2016) who document a "de-skilling process" according to which traditionally lower-skilled occupations have seen a particularly large growth in the share of highly educated individuals. ${ }^{24}$

Another, and potentially more powerful, approach to conduct a test of sorting as suggested by our model is using panel data. We use the 1980-1997 Panel Study of Income Dynamics (PSID) and consider two time periods: 1980-1985 and 1992-1997. We restrict the sample to male workers, aged 16-64, working in a complex occupation in period $t$, and having experienced a 3 -digit occupational switch from period $t-1$ to period $t$ into their current complex occupation either from a simple occupation or from another complex occupation. We then run the following regression:

$$
\ln w_{t}=\beta_{0}+\beta_{1} \text { Dum }_{s c}+\beta_{2} \text { Dum }_{\text {time }}+\beta_{3} \text { Dum }_{\text {sc }} * \text { Dum }_{\text {time }}+\beta_{4} X_{t},
$$

where $\ln w_{t}$ is the log real hourly wage in period $t, D u m_{s c}$ is a dummy variable that takes the value of one if the occupational switch into the current complex occupation is from a simple occupation

\footnotetext{
${ }^{24}$ We have also estimated richer models of the changing education composition between simple and complex occupations. In particular, using pooled individual level data for 1980 and 2005 we have run linear probability models of the complex occupation dummy on a dummy for high school educated workers, a dummy for workers with at least some post-secondary educational attainment, a polynomial in age, a dummy for the year 2005, and interactions between the time- and education dummies. The results from these specifications are in line with those documented in Table E.1. In particular, the share of high school educated workers, that is those likely to be most likely at the margin between simple- and complex occupation employment, has increased faster in simple occupations, holding constant the share of highly educated. Hence, there was a faster reallocation from low- to medium-skilled labor in simple than in complex occupations. Interestingly, we also find that younger workers also reallocated at a higher rate to complex occupations than older workers, which we view as further evidence in favor of our proposed mechanism if we view age as a variable correlated with human capital and skill.
} 
and zero otherwise, Dum time is a dummy variable that takes the value of one in the 1992-1997 time period, and $X_{t}$ is a vector of covariates that includes five age groups, education, race, number of children, and health. The parameter of interest is the coefficient on the interaction term. This specification can be motivated as follows. According to our model, workers going to complex occupations become over time, on average, less skilled at solving complex tasks. First, in the empirical model in (E.1) we use those who switch from simple to complex occupations as "standins" for such marginal workers. However, occupational switches may always come with systematic wage gains or losses, and these gains may have changed over time. Therefore, we use occupational switchers within complex occupations to control for this component. Second, the interaction term measures the extent to which the wage gap between these two groups of switchers has changed over time.

Table E.2: Change in Average Wages by Occupation

\begin{tabular}{|c|c|c|}
\hline \multicolumn{3}{|c|}{ Dependent Variable: Log Wages } \\
\hline & (i) & (ii) \\
\hline$D_{u m}$ & $-0.339 * * *$ & $-0.129 * * *$ \\
\hline Dum $_{\text {time }}$ & $0.134^{* * *}$ & $0.060^{* *}$ \\
\hline Dum $_{s c} *$ Dum $_{\text {time }}$ & $-0.101^{* * *}$ & $-0.118^{* *}$ \\
\hline Age & & $0.131^{* *}$ \\
\hline Education & & $0.071^{* * *}$ \\
\hline Race & & $-0.099 * * *$ \\
\hline Children & & $0.030^{* * *}$ \\
\hline Health & & $-0.046^{* * *}$ \\
\hline \multicolumn{3}{|c|}{ significance level: ${ }^{* * *} 1 \%,{ }^{* *} 5 \%$} \\
\hline
\end{tabular}

Notes: Regressions run on 1980-1997 PSID data

Column (i) in Table E.2 provides the basic results from the regression. In the first time period, within the group of occupational switchers into a complex occupation in period $t$, those that switched from a simple occupation had 34\% lower wages in period $t$ than those that switched from another complex occupation. The main result from our test is in the interaction coefficient - in the second time period that wage gap increased by another 10 percentage points. In other words, switchers from simple to complex occupations earn additional 10 percentage points less than switchers from complex to complex occupations in the second period than in the first period. 
Column (ii) in Table E.2, listing a specification where we control for several observables, ${ }^{25}$ does not change our main results: the wage gap between switchers from complex to complex occupations and switchers from simple to complex occupations has increased over time. We interpret this result as indirect supporting evidence of the fact that the marginal worker that works in a complex occupation in the late 1990s has a lower level of skill complexity than the marginal worker in the early 1980 s.

\footnotetext{
${ }^{25}$ Note also that since we restrict the sample to occupational switchers into a complex occupation, they all have the same occupational tenure.
} 


\section{F Tables and Figures}

Table F.1: Group-Level Employment Growth Regression

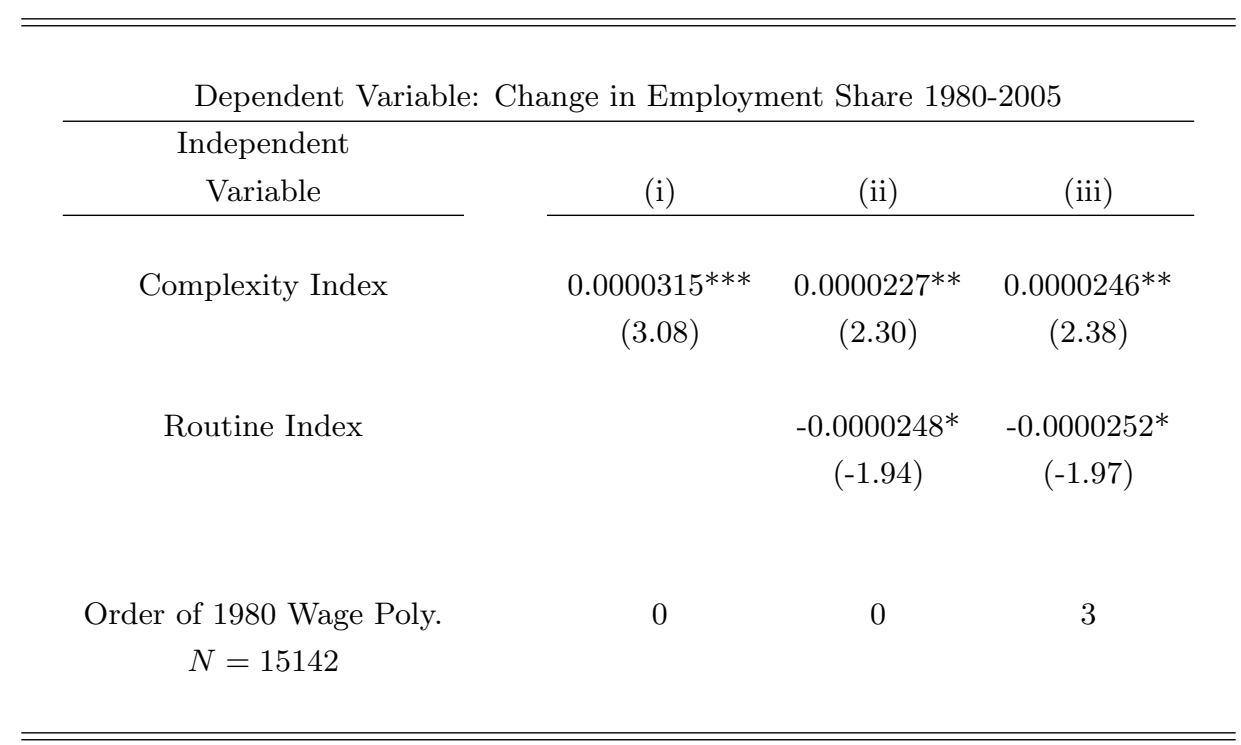

Notes: The table reports results when occupation-level data is disaggregated to occupation $\times$ gender $\times$ education $\times$ race $\times$ age cells (see section 3.2 for discussion). Regressions include gender $\times$ education $\times$ race $\times$ age fixed effects.

Sandard errors clustered at the occupation level. t-statistics are in parentheses.

Significance levels are: ${ }^{* * *} 1 \%,{ }^{* *} 5 \%,{ }^{*} 10 \%$. 
Table F.2: Occupation-Level Employment Growth Regression by 1980 Wage Tercile

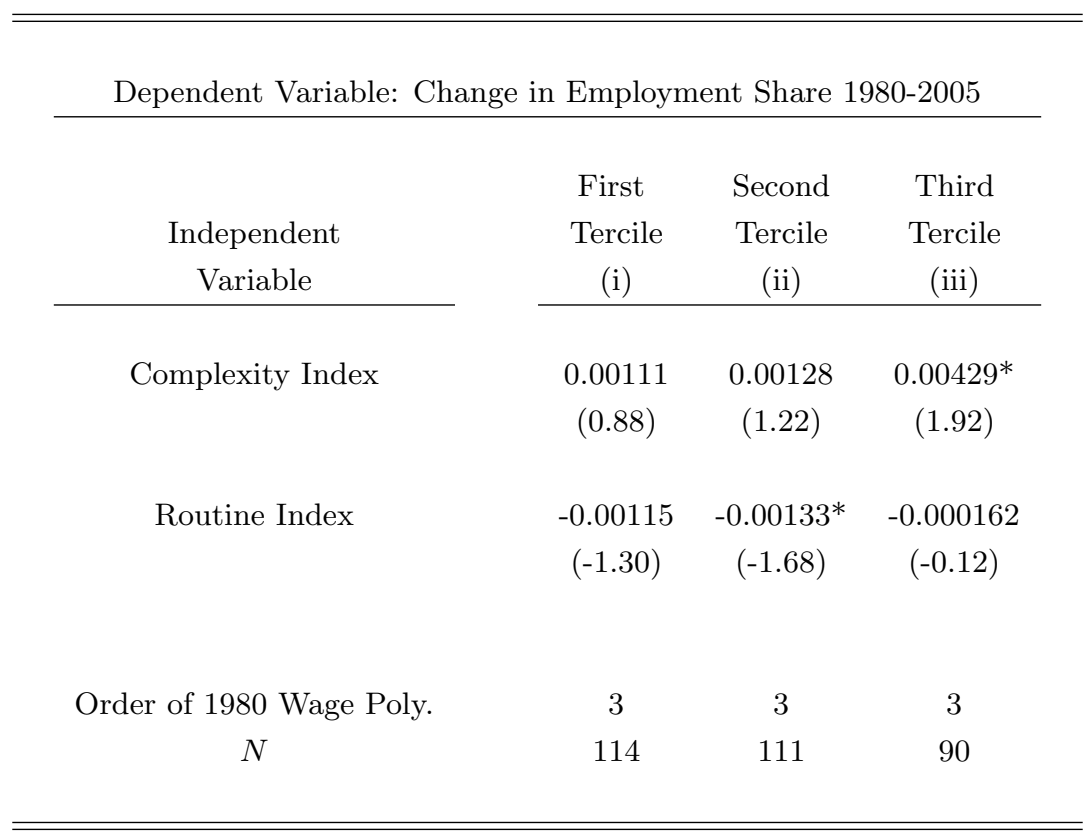

Notes: The table reports results for occupation-level regressions run for different terciles of the 1980 occupational wage distribution. t-statistics are in parentheses. Significance levels are: ${ }^{* * *} 1 \%,{ }^{* *} 5 \%,{ }^{*} 10 \%$. 
Table F.3: Occupation-Level Wage Growth Regression with Occupational Demographic Means: Female-Only Sample

\begin{tabular}{|c|c|c|c|c|c|}
\hline \multicolumn{6}{|c|}{ Dependent Variable: Change in Log Wages 1980-2005 } \\
\hline Independent & \multicolumn{3}{|c|}{$\begin{array}{c}\text { Complex Variable: } \\
\text { Index }\end{array}$} & \multicolumn{2}{|c|}{$\begin{array}{c}\text { Complex Variable: } \\
\text { Indicator }^{\dagger}\end{array}$} \\
\hline Variable & (i) & (ii) & (iii) & (iv) & $(\mathrm{v})$ \\
\hline Complexity Variable & $\begin{array}{c}0.365^{* * *} \\
(5.25)\end{array}$ & $\begin{array}{c}0.364^{* * *} \\
(5.14)\end{array}$ & $\begin{array}{c}0.380 * * * \\
(5.35)\end{array}$ & $\begin{array}{c}0.0941^{* * *} \\
(2.75)\end{array}$ & $\begin{array}{c}0.121^{* * *} \\
(3.45)\end{array}$ \\
\hline Routine Index & & $\begin{array}{c}-0.00457 \\
(-0.09)\end{array}$ & $\begin{array}{l}-0.0182 \\
(-0.36)\end{array}$ & $\begin{array}{l}-0.0421 \\
(-0.82)\end{array}$ & $\begin{array}{l}-0.0279 \\
(-0.54)\end{array}$ \\
\hline Female Share & $\begin{array}{l}-0.0477 \\
(-0.96)\end{array}$ & $\begin{array}{l}-0.0465 \\
(-0.90)\end{array}$ & $\begin{array}{c}-0.101^{* *} \\
(-1.99)\end{array}$ & $\begin{array}{c}-0.115^{* *} \\
(-2.21)\end{array}$ & $\begin{array}{c}-0.116^{* *} \\
(-2.24)\end{array}$ \\
\hline College Share & $\begin{array}{c}0.183^{* *} \\
(2.08)\end{array}$ & $\begin{array}{c}0.181^{* *} \\
(2.00)\end{array}$ & $\begin{array}{c}0.312^{* * *} \\
(3.14)\end{array}$ & $\begin{array}{c}0.455^{* * *} \\
(4.68)\end{array}$ & $\begin{array}{c}0.383^{* * *} \\
(3.77)\end{array}$ \\
\hline High School Share & $\begin{array}{l}-0.0724 \\
(-0.47)\end{array}$ & $\begin{array}{l}-0.0706 \\
(-0.45)\end{array}$ & $\begin{array}{c}0.0860 \\
(0.53)\end{array}$ & $\begin{array}{l}0.213 \\
(1.28)\end{array}$ & $\begin{array}{l}0.267 \\
(1.65)\end{array}$ \\
\hline Non-white Share & $\begin{array}{l}-0.214 \\
(-0.85)\end{array}$ & $\begin{array}{l}-0.215 \\
(-0.85)\end{array}$ & $\begin{array}{c}0.00986 \\
(0.04)\end{array}$ & $\begin{array}{l}0.0627 \\
(0.24)\end{array}$ & $\begin{array}{l}0.110 \\
(0.43)\end{array}$ \\
\hline Married Share & $\begin{array}{l}-0.414 \\
(-1.32)\end{array}$ & $\begin{array}{l}-0.409 \\
(-1.29)\end{array}$ & $\begin{array}{l}0.133 \\
(0.41)\end{array}$ & $\begin{array}{l}0.305 \\
(0.91)\end{array}$ & $\begin{array}{l}0.348 \\
(1.06)\end{array}$ \\
\hline Mean Age & $\begin{array}{c}0.00290 \\
(0.59)\end{array}$ & $\begin{array}{c}0.00289 \\
(0.59)\end{array}$ & $\begin{array}{c}-0.000432 \\
(-0.09)\end{array}$ & $\begin{array}{c}-0.00170 \\
(-0.34)\end{array}$ & $\begin{array}{c}-0.00285 \\
(-0.58)\end{array}$ \\
\hline Mean \# Children & $\begin{array}{r}0.244^{*} \\
(1.76)\end{array}$ & $\begin{array}{l}0.242^{*} \\
(1.72)\end{array}$ & $\begin{array}{l}0.131 \\
(0.96)\end{array}$ & $\begin{array}{l}0.137 \\
(0.97)\end{array}$ & $\begin{array}{l}0.104 \\
(0.74)\end{array}$ \\
\hline $\begin{array}{l}\text { Order of } 1980 \text { Wage Poly. } \\
\qquad N=310\end{array}$ & 0 & 0 & 3 & 3 & 3 \\
\hline
\end{tabular}

$\dagger$ Complex occupations are defined as those above the 50th percentile (column (iv)) or above the 66th percentile (column (v)) of the complexity index.

Notes: Demographic variables are occupation-level means of the share of workers in an occupation with a college/high-school degree, the share of workers in an occupation who are non-white, the share of workers in an occupation who are married, the share of female workers in an occupation, the mean age of workers in an occupation, and the mean number of children of workers in an occupation. t-statistics are in parentheses. Significance levels are: ${ }^{* * *} 1 \%,{ }^{* *} 5 \%,{ }^{*} 10 \%$. 
Table F.4: Occupation-Level Employment Growth Regression with Occupational Demographic Means: Female-Only Sample

Dependent Variable: Change in Employment Share 1980-2005

\begin{tabular}{|c|c|c|c|c|c|}
\hline \multirow{2}{*}{$\begin{array}{c}\text { Independent } \\
\text { Variable }\end{array}$} & \multicolumn{3}{|c|}{$\begin{array}{c}\text { Complexity Variable: } \\
\text { Complexity Index }\end{array}$} & \multicolumn{2}{|c|}{$\begin{array}{l}\text { Complexity Variable: } \\
\text { Complex Indicator }^{\dagger}\end{array}$} \\
\hline & (i) & (ii) & (iii) & (iv) & (v) \\
\hline Complexity Variable & $\begin{array}{c}0.00179 \\
(1.16)\end{array}$ & $\begin{array}{c}0.00120 \\
(0.77)\end{array}$ & $\begin{array}{l}0.000970 \\
(0.59)\end{array}$ & $\begin{array}{c}0.000476 \\
(0.63)\end{array}$ & $\begin{array}{c}0.000796 \\
(1.01)\end{array}$ \\
\hline Routine Index & & $\begin{array}{c}-0.00245^{* *} \\
(-2.10)\end{array}$ & $\begin{array}{c}-0.00243^{* *} \\
(-2.07)\end{array}$ & $\begin{array}{c}-0.00245^{* *} \\
(-2.10)\end{array}$ & $\begin{array}{c}-0.00233^{* *} \\
(-1.98)\end{array}$ \\
\hline Female Share & $\begin{array}{c}-0.00353^{* * *} \\
(-3.16)\end{array}$ & $\begin{array}{c}-0.00289^{* *} \\
(-2.51)\end{array}$ & $\begin{array}{c}-0.00318^{* * *} \\
(-2.68)\end{array}$ & $\begin{array}{c}-0.00321^{* * *} \\
(-2.71)\end{array}$ & $\begin{array}{c}-0.00320^{* * *} \\
(-2.70)\end{array}$ \\
\hline College Share & $\begin{array}{c}0.00472^{* *} \\
(2.40)\end{array}$ & $\begin{array}{c}0.00376^{*} \\
(1.87)\end{array}$ & $\begin{array}{c}0.00425^{*} \\
\quad(1.83)\end{array}$ & $\begin{array}{c}0.00447^{* *} \\
(2.02)\end{array}$ & $\begin{array}{c}0.00390^{*} \\
(1.68)\end{array}$ \\
\hline High School Share & $\begin{array}{c}-0.00307 \\
(-0.90)\end{array}$ & $\begin{array}{c}-0.00215 \\
(-0.63)\end{array}$ & $\begin{array}{c}-0.00126 \\
(-0.34)\end{array}$ & $\begin{array}{c}-0.00118 \\
(-0.32)\end{array}$ & $\begin{array}{c}-0.000953 \\
(-0.26)\end{array}$ \\
\hline Non-white Share & $\begin{array}{c}0.00453 \\
(0.80)\end{array}$ & $\begin{array}{c}0.00434 \\
(0.77)\end{array}$ & $\begin{array}{c}0.00584 \\
(1.00)\end{array}$ & $\begin{array}{c}0.00588 \\
(1.01)\end{array}$ & $\begin{array}{c}0.00614 \\
(1.06)\end{array}$ \\
\hline Married Share & $\begin{array}{c}-0.00683 \\
(-0.97)\end{array}$ & $\begin{array}{c}-0.00446 \\
(-0.63)\end{array}$ & $\begin{array}{c}-0.00156 \\
(-0.20)\end{array}$ & $\begin{array}{c}-0.00138 \\
(-0.18)\end{array}$ & $\begin{array}{c}-0.00127 \\
(-0.17)\end{array}$ \\
\hline Mean Age & $\begin{array}{l}0.0000220 \\
\quad(0.20)\end{array}$ & $\begin{array}{c}0.0000174 \\
(0.16)\end{array}$ & $\begin{array}{c}-0.000000999 \\
(-0.01)\end{array}$ & $\begin{array}{c}-0.00000376 \\
(-0.03)\end{array}$ & $\begin{array}{c}-0.0000122 \\
(-0.11)\end{array}$ \\
\hline Mean \# Children & $\begin{array}{c}0.00229 \\
(0.75)\end{array}$ & $\begin{array}{c}0.00125 \\
(0.41)\end{array}$ & $\begin{array}{c}0.000523 \\
(0.16)\end{array}$ & $\begin{array}{l}0.000576 \\
(0.18)\end{array}$ & $\begin{array}{c}0.000397 \\
(0.13)\end{array}$ \\
\hline $\begin{array}{l}\text { Order of } 1980 \text { Wage Poly. } \\
\qquad N=315\end{array}$ & 0 & 0 & 3 & 3 & 3 \\
\hline
\end{tabular}

${ }^{\dagger}$ Complex occupations are defined as those above the 50th percentile (column (iv)) or above the 66th percentile (column (v)) of the complexity index.

Notes: Demographic variables are occupation-level means of the share of workers in an occupation with a college/high-school degree, the share of workers in an occupation who are non-white, the share of workers in an occupation who are married, the share of female workers in an occupation, the mean age of workers in an occupation, and the mean number of children of workers in an occupation. t-statistics are in parentheses. Significance levels are: *** $1 \%,{ }^{* *} 5 \%,{ }^{*} 10 \%$. 
Table F.5: Employment Growth Regression with Social Skills

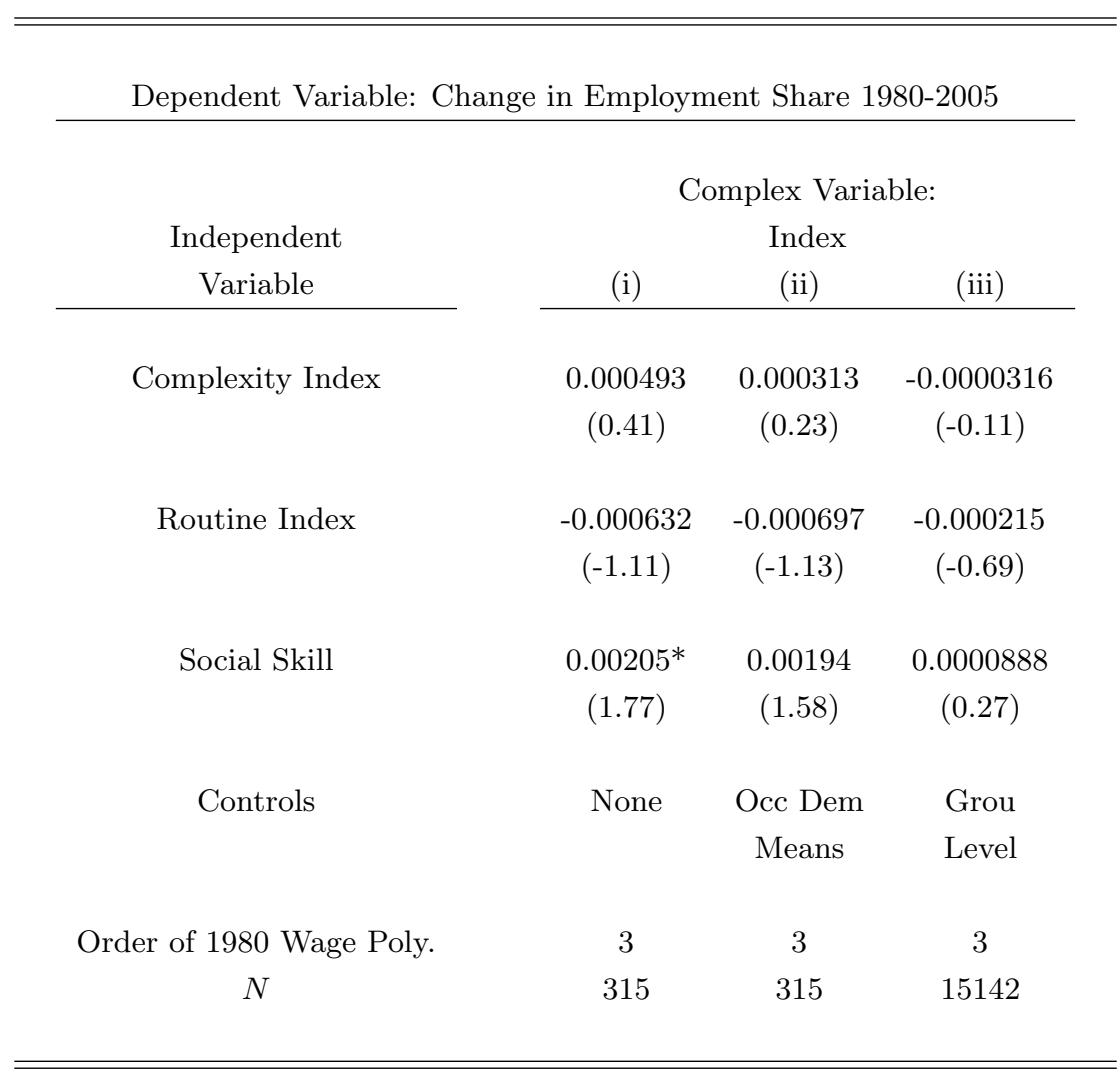

Notes: t-statistics are in parentheses. Significance levels are: ${ }^{* * *} 1 \%,{ }^{* *} 5 \%,{ }^{*} 10 \%$. (i) occupation-level regression.

(ii) occupation-level regression with the following demographic controls: share of workers in an occupation with a college/high-school degree, share of workers in an occupation who are non-white, share of workers in an occupation who are married, share of female workers in an occupation, mean age of worker in an occupation, and mean number of children of workers in an occupation.

(iii) group-level regression on occupation $\times$ gender $\times$ education $\times$ race $\times$ age cells $($ see section 3.2 for discussion). Regressions include gender $\times$ education $\times$ race $\times$ age fixed effects. Standard errors clustered at the occupation level. 